Saliba, N. and Gardner, L. (2013). Experimental study of the shear response of lean duplex stainless steel plate girders. Engineering Structures. 46, 375-391.

\title{
Experimental study of the shear response of lean duplex stainless steel plate girders
}

\author{
N. Saliba ${ }^{1}$ and L. Gardner ${ }^{1}$ \\ ${ }^{1}$ Department of Civil and Environmental Engineering, Imperial College London, London, SW7 2AZ, \\ UK. \\ Corresponding author: Prof Leroy Gardner, Department of Civil and Environmental Engineering, \\ Imperial College London, London, SW7 2AZ, UK. Email: Leroy.gardner@imperial.ac.uk
}

\begin{abstract}
An experimental and numerical study of the shear response of lean duplex stainless steel plate girders is described in this paper. A total of nine welded plate girders were tested. Lean duplex stainless steel, which is a low nickel variety of the material, has approximately twice the strength of the common austenitic grades and at approximately half the initial cost. It also possesses good corrosion resistance and high temperature properties, as well as adequate weldability and fracture toughness. Two web panel aspect ratios and a range of web slendernesses were considered. The results from the experiments, including the full load-deformation histories and failure models are reported. A numerical investigation was carried out in parallel with the testing. The models were first validated against the experimental results after which parametric studies were performed to generate data for a wider range of cross-sections. The generated experimental and numerical data were used to assess the shear resistance design equations given in Eurocode 3: Part 1.4. The current design provisions were shown to be safely applicable to lean duplex stainless steel, though improved guidance is sought in further ongoing research.
\end{abstract}


Keywords: Experiments, Failure modes, Finite element, Lean duplex, Numerical modelling, Shear buckling, Stainless steel, Structural testing, Ultimate shear capacity, Welded I-sections,.

\section{Introduction}

Stainless steel has a range of physical characteristics such as high strength, stiffness, and ductility together with excellent durability that makes it ideally suited to use in construction [1]. However, due to the high initial cost of structural stainless steel compared to that of structural carbon steel, and the relatively limited awareness of its credentials among structural engineers, the use of stainless steel in construction remains rather restricted. The high initial cost of stainless steel is largely attributed to the nickel content which, for the commonly used grades of austenitic stainless steel, lies between about $8 \%$ and $10 \%$ by mass. A new breed of stainless steel has been developed with low nickel content (around 1.5\%), which may offer improved economy over existing grades. The material, referred to as lean duplex stainless steel, possesses higher strength than the austenitic grades, is less expensive, retains good corrosion resistance and high temperature properties, and has adequate weldability and fracture toughness [2-4].

Although lean duplex stainless steel has already featured in the construction of a number of footbridges, and is included in the material standard EN 10088-4 [5], it is not currently covered by any structural design code, due to its structural characteristics having been largely unverified. In order to overcome this, a comprehensive programme of experimental and numerical research is underway at Imperial College London to investigate the structural performance of lean duplex stainless steel. Initial research concentrated on cold-formed hollow sections $[6,7]$, while more recently the focus has moved to welded I-sections [8] and, in the present paper, plate girders. Other recent studies of cold-formed lean duplex stainless steel hollow sections have been performed by Huang and Young [9] and Patton and Singh [10].

The present paper examines the behaviour of lean duplex stainless steel welded plate girders through experimentation and finite element (FE) modelling. Unlike in the case of carbon steel, the shear behaviour of stainless steel plate girders has only received 
relatively limited attention, and no previous experiments have been conducted on plate girders fabricated from lean duplex material. Structural testing has been carried out on austenitic and duplex stainless steel plate girders by Olsson [11], Real et al. [12], and Estrada et al. [13], while recent numerical studies have been undertaken by Hassanein [14]. Structural design rules for stainless steel plate girders are relatively scarce; the provisions of Eurocode 3: Part 1.4 [15], and their applicability to lean duplex stainless steel are examined later in this paper. First, structural performance data are generated through laboratory testing and numerical modelling, as described in Sections 2 and 3 of this paper.

\section{Experimental programme}

An experimental programme, compromising material tests, measurements of geometric imperfections and plate girder tests, is described in this section.

\subsection{Material testing}

A series of tests on tensile and compressive coupons extracted from the plate material used to form the structural cross-sections was carried out in the Structures Laboratory of the Department of the Civil and Environmental Engineering at Imperial College London. The coupon tests were used to obtain the basic stress-strain properties and to analyze the nonlinear material behaviour of lean duplex stainless steel. A total of twenty-eight coupons of seven material thicknesses $(4 \mathrm{~mm}, 6 \mathrm{~mm}, 8 \mathrm{~mm}, 10 \mathrm{~mm}, 12$ $\mathrm{mm}, 15 \mathrm{~mm}$, and $20 \mathrm{~mm}$ ) were tested in tension and compression. For each thickness, two tensile coupons and two compressive coupons were tested. Tests were performed on both longitudinal (i.e. parallel to the rolling direction) and transverse (i.e. perpendicular to the rolling direction) coupons, following the provisions of EN 100021 [16]. The nominal dimensions of the necked tensile coupons were $340 \times 30 \mathrm{~mm}$ while the nominal dimensions of the compressive coupons were $72 \times 16 \mathrm{~mm}$. For the thicker coupons $(15 \mathrm{~mm}$ and $20 \mathrm{~mm})$ the tests were carried out in an INSTRON $600 \mathrm{kN}$ machine, whereas for the remaining coupons the tests were carried out in an INSTRON $250 \mathrm{kN}$ machine. The initial strain rate used for all of the material tests was $0.0003 \mathrm{~s}^{-1}$, increasing after $1 \%$ strain to a strain rate of $0.008 \mathrm{~s}^{-1}$. The tensile coupons were marked 
with proportional gauge lengths to calculate their plastic strain at fracture $\varepsilon_{\mathrm{f}}$ after testing, based on elongation over the standard gauge length $5.65 \sqrt{A_{c}}$, where $A_{c}$ is the cross-sectional area of the coupon. Tensile strain was measured by means of a digital extensometer. The compressive coupons were tested in a bracing jig to prevent buckling; strain gauges were attached to both sides of the tested coupons at mid-height. All test data, including load, displacement, strain and input voltage were recorded at one-second intervals using the data acquisition system DATASCAN. The obtained material data for each of the tensile and compressive test specimens, together with the mill certificate material properties provided by the manufacturer, are given in Tables 1 and 2, where $E$ is Young's modulus, $\sigma_{0.2}$ is the $0.2 \%$ proof stress, $\sigma_{1.0}$ is the $1.0 \%$ proof stress, $\sigma_{\mathrm{u}}$ is the ultimate tensile stress, $\varepsilon_{\mathrm{f}}$ is the plastic strain at fracture based on elongation over the standard gauge length and $\mathrm{n}$ and $\mathrm{n}^{\prime}{ }_{0.2,1.0}$ are strain hardening exponents for the compound Ramberg-Osgood model $[17,18]$ as modified by Gardner and Ashraf [19]. The stress-strain curves for each of the tested thicknesses are presented in Figs 1-7.

A comparison between the results obtained from the measured tensile and compressive material tests for the $0.2 \%$ and $1 \%$ proof stress shows that generally the results of the longitudinal coupons are lower than those of the transverse coupons. Furthermore, the measured $0.2 \%$ proof stress from the transverse coupons tests were found to be relatively similar to those stated in the mill certificates, whereas the longitudinal coupons were found to be generally lower. This is consistent with the fact that mill tests are performed in the transverse direction. Strain rates are also typically higher in mill tests than laboratory testing programmes. The mean measured values of the RambergOsgood $\mathrm{n}$ and $\mathrm{n}_{0.2,1.0}$ parameters for the tested plate material were 10.5 and 2.6 respectively with some variation depending on rolling (longitudinal or transverse) and loading (tension or compression) directions. The obtained values are close to those reported by Saliba and Gardner [8] $\left(\mathrm{n}=10.0\right.$ and $\left.\mathrm{n}_{0.2,1.0}=2.0\right)$ following coupon tests on similar lean duplex stainless steel plate material used to form welded I-sections. The values reported by Theofanous and Gardner [6, 7] from tests on cold-formed lean duplex stainless steel hollow section material $\left(\mathrm{n}=7.0\right.$ and $\left.\mathrm{n}_{0.2,1.0}=3.3\right)$, indicate a more rounded stress-strain response, which is typical of cold-formed material. 


\subsection{Plate girder tests}

The material examined in the previous section was used to fabricate nine lean duplex stainless steel plate girders. The fillet welds between the flanges and web were made using submerged arc welding with weld material $2293 \mathrm{LN}$, designated according to EN 12072 [20]. The stiffeners were MIG welded using the same weld material. Prior to testing, the basic geometry of the plate girders was carefully measured. The key measurements can be found in Table 3 where, with reference to Fig. 8, $\mathrm{L}$ is the specimen length, $\mathrm{a}$ is the web panel length, $\mathrm{e}$ is the distance between the end post and the internal stiffener over the support, $b$ is the overall flange width, $h_{w}$ is the web depth, $t_{f}$ is the thickness of the flanges, $t_{w}$ is the thickness of the web, $b_{s}=\left(b-t_{w}\right) / 2$ is the width of the stiffeners and $t_{s}$ is the thickness of the stiffeners. Local geometric imperfections were not analysed in detail but approximate sample measurements found imperfection amplitudes to be similar to those observed in lean duplex stainless steel welded Isections tested previously by Saliba and Gardner [8], which were fabricated in the same manner.

A total of eighteen strain gauges were attached to each of the plate girders at critical points, and were used to monitor the development of the shear buckling phenomenon during the tests and to validate the numerical models. All sections had Class 4 webs in bending according to EN 1993-1-4 [15], with the exception of Specimen I$600 \times 200 \times 15 \times 15-2$, for which the web was Class 3 . Rigid end post conditions, satisfying the requirements of EN 1993-1-5 [21] for carbon steel plate girders, were achieved through the provision of a pair of transverse web stiffeners at each support. The tests were carried out to generate data in order to assess the applicability of the current design methods available for stainless steel plate girders to the lean duplex grades and to understand further the general behaviour of stainless steel plate girders failing in shear.

Two sets of specimens were tested - the first set had four specimens with a web panel aspect ratio $\mathrm{a} / \mathrm{h}_{\mathrm{w}}=1.0$, while the second set had five specimens with a web panel aspect ratio $\mathrm{a} / \mathrm{h}_{\mathrm{w}}=2.0$. The plate girders with web panels of aspect ratio 1.0 were $1360 \mathrm{~mm}$ in length, whereas those of aspect ratio 2.0 were $2560 \mathrm{~mm}$ in length. For each of the tested plate girders, instrumentation was provided in one panel only, while shear buckling was 
inhibited in the adjacent panel through the addition of wooden diagonal planks. A total of eighteen strain gauges were attached to each of the plate girders at critical points to monitor the development of the shear buckling phenomenon during the tests. Ten triaxial (rosette) strain gauges were attached to the web panel - five on each side, to measure the membrane and bending components of strains in the web. Three of the five triaxial strain gauges were placed along the central vertical axis of the web panel. These strain gauges were used to study the development of the shear stress state and the inclination of the tension band once shear buckling occurs. The other two triaxial strain gauges were located at the corner of the web panel to examine anchorage of the tension field. Eight uniaxial strain gauges were attached to the flanges and stiffeners; the strain gauges in the flanges were used to monitor the formation of plastic hinges. The locations of each of the above mentioned strain gauges are shown in Fig. 9, in which $g$ defines the positions of the strain gauges and $\mathrm{c}$ is the calculated distance from the stiffener to the plastic hinge location, determined according to EN 1993-1-4 [15]. Furthermore, for each of the tested plate girders, six Linear Variable Displacement Transducers (LVDTs) were employed to measure the vertical and horizontal displacements. Three LVDTs were used to measure vertical displacements - one at mid-span and one at each of the two supports. The other three LVDTs were located horizontally along the mid-height of the web panel to measure the out-of-plane lateral displacements associated with the shear buckling. Two string potentiometers were employed to measure the change in length of the two diagonals of the web panels, and hence to estimate the average shear strain. Finally, two inclinometers were placed at each end of the beam in order to determine the rotation at the support points. The general scheme of the LVDTs, string potentiometers and inclinometers can be found in Fig. 10.

The tests were carried out in an ENERPAC $4000 \mathrm{kN}$ machine controlled by a Walter + Bai ag DIGICON 2000 digital controller. The tests were load-controlled at a rate of 10 $\mathrm{kN} / \mathrm{sec}$, and by regulating the flow rate into the hydraulic jack, the unloading response could be captured. The load was applied through a bearing plate, which was $200 \mathrm{~mm}$ wide (equal to the flange width), $100 \mathrm{~mm}$ in length and $50 \mathrm{~mm}$ thick. Loads, rotations, displacements and strains were all recorded at one-second intervals using the data acquisition system DATASCAN. The employed specimen designation system begins 
with the section type, followed by section depth $\times$ flange width $\times$ flange thickness $\times$ web thickness, and finally the web panel aspect ratio (1 or 2).

The key experimental results from the plate girder tests are summarised in Table 3, where $\mathrm{V}_{\text {cr }}$ is the calculated elastic critical shear buckling load of the web, $\mathrm{V}_{\mathrm{u}, \text { test }}$ and $\mathrm{M}_{\mathrm{u}, \text { test }}$ are the shear force and bending moment, respectively, at failure from the experiments and $\mathrm{c}_{\text {test }}$ is the measured horizontal dimension from the support stiffener to the plastic hinge that formed in the flange at collapse. The observed failure modes, which are discussed further in Section 4.2, are also included in Table 3. The obtained load-displacement curves from the two series of tests $-\mathrm{a} / \mathrm{h}_{\mathrm{w}}=1.0$ and $\mathrm{a} / \mathrm{h}_{\mathrm{w}}=2.0-$ are shown in Figs 11-14. Figs 11 and 12 show load versus mid-span vertical deflection, while Figs 13 and 14 show load versus lateral deflection of the web. The results of the experiments are employed for the validation of the numerical models in Section 3 of this paper and are analysed and discussed in Section 4, where typical failure modes are also shown.

\section{Numerical modelling}

\subsection{Basic modelling assumptions}

The experiments described in the previous section were supplemented by a numerical study using the general-purpose finite element analysis package ABAQUS [22]. The experiments were initially used to validate the FE models. Following the successful validation of the numerical models, parametric studies were carried out to assess the influence of key parameters on the structural response of lean duplex stainless steel plate girders. Furthermore, the parametric studies were used to expand the available structural performance data over a wider range of web slendernesses and to consider different end post conditions.

The finite element type used for the numerical analyses was the four-noded doubly curved general-purpose shell element S4R with finite membrane strains. This element has been shown to be suitable for the modelling of a range of shell thicknesses and has 
been successfully employed in the modelling of lean duplex stainless steel welded Isections [8] and other similar structural components [6, 7, 23, 24].

The FE models were initially developed based on the measured geometry of the tested plate girders. For all of the FE models reported in this paper the stress-strain response of the lean duplex stainless steel was represented initially by means of the two-stage Ramberg-Osgood model described by Gardner and Ashraf [19]. For incorporation into ABAQUS, the continuous curve was approximated with a multi-linear model defined in terms of true stress and log plastic strain. The relationship between true stress and engineering stress, $\sigma_{\text {true }}$ and $\sigma_{\text {nom, }}$, respectively, is given by Eq. (1), while the relationship between $\log$ plastic strain and engineering strain, $\varepsilon_{\ln }^{\mathrm{pl}}$ and $\varepsilon_{\text {nom }}$, respectively, is given by Eq. (2), where $\sigma_{\text {nom }}$ and $\varepsilon_{\text {nom }}$ are the engineering stress and strain respectively and $E$ is the Young's modulus. The material properties incorporated into the FE models were based on the average of the longitudinal and transverse coupon test results, with tensile material properties applied to the lower halves of the models and compressive material properties applied to the upper halves.

$$
\begin{aligned}
& \sigma_{\text {true }}=\sigma_{\text {nom }}\left(1+\varepsilon_{\text {nom }}\right) \\
& \varepsilon_{\text {ln }}^{\mathrm{pl}}=\ln \left(1+\varepsilon_{\text {nom }}\right)-\frac{\sigma_{\text {true }}}{E}
\end{aligned}
$$

Boundary conditions were carefully incorporated into the FE models to replicate the experimental setup. The load was applied at the centre of the FE models through a bearing plate (similar to the experimental setup; see Section 2.2 and Fig. 8). Vertical and lateral displacements were restrained at the supports, while longitudinal displacements and rotation about the horizontal axes were restrained at mid-span.

Initial geometric imperfections, arising principally during production and fabrication, are present in all structural members and influence their structural response. Therefore, it is necessary to account for these imperfections in any numerical modelling study. This is commonly achieved by first performing a linear eigenvalue buckling analysis to determine the lowest relevant elastic buckling mode, and subsequently incorporating the obtained shape as the geometric imperfection, with a chosen amplitude, in the 
nonlinear analysis; this was the approach adopted in the present study. Owing to the absence of global (member) buckling, only local geometric imperfections were incorporated in the FE models. The modified Riks method [22], which is an algorithm that enables effective solutions to be found to unstable problems and adequately traces nonlinear unloading paths, was used in the nonlinear analyses. The imperfection amplitude employed in this study was the one derived from the Dawson and Walker model [25], as modified by Gardner and Nethercot [26], defined by Eq. (3), where $\sigma_{0.2}$ is the tensile $0.2 \%$ proof stress and $\sigma_{\mathrm{cr}}$ is the elastic critical buckling stress of the most slender constituent plate element in the section, determined on the basis of the flat width of the element. This imperfection amplitude prediction model has been successfully employed for the modelling of lean duplex stainless steel welded I-sections in compression and bending [8], and further similar applications [6, 7, 27]. The imperfection amplitude $\omega_{\mathrm{D} \& \mathrm{~W}}$ is given by Eq. (3) and presented in Table 4.

$\omega_{\mathrm{D} \& \mathrm{~W}}=0.023\left(\sigma_{0.2} / \sigma_{\mathrm{cr}}\right) \mathrm{t}$

The study by Saliba and Gardner [8] accounted for residual stresses in the modelling of the lean duplex stainless steel welded I-sections but found insignificant variation in structural behaviour when models with and without residual stresses were compared. It was therefore concluded that residual stresses need not be included in the models, and the same approach is taken herein.

\subsection{Validation of models}

The accuracy of the numerical models and their suitability for performing parametric studies was initially assessed by comparing the experimental results to those generated by the FE simulations. The comparisons were based on the general load-displacement curves and failure modes, as well as other key values such as the ultimate shear force, denoted $V_{u, t e s t}$ and $V_{u, F E}$ for the experimental and numerical results, respectively. Note that for the present loading configuration, maximum shear force is simply equal to half the applied load. The ratio of the numerical to experimental ultimate shear forces $\left(\mathrm{V}_{\mathrm{u}, \mathrm{FE}} / \mathrm{V}_{\mathrm{u}, \text { test }}\right)$ is presented in Table 4 . The ultimate shear force is generally very well predicted with the Dawson and Walker imperfection amplitude model, with a mean value of $\mathrm{V}_{\mathrm{u}, \mathrm{FE}} / \mathrm{V}_{\mathrm{u} \text {,test }}$ of 1.00 and a coefficient of variation $(\mathrm{COV})$ of 0.03 . The failure 
modes obtained from the numerical models showed good agreement with those obtained from the experiments. Typical FE failure modes for the plate girders of aspect ratios 1.0 and 2.0 are shown in Figs 15 and 16, respectively. The general shapes of the load-deflection curves from the FE models also closely matched those obtained from experiments. A comparison between the experimental and numerical loaddisplacements curves for specimens I- $600 \times 200 \times 12 \times 8-1$ and I- $600 \times 200 \times 12 \times 8-2$ are depicted in Figs 17 and 18, respectively.

The principal strains obtained from the rosette strain gauges at the centre and corner of the tested web panels were also compared with the values extracted from the corresponding locations in the FE models; close agreement was observed, as shown for specimen I- $600 \times 200 \times 12 \times 8-1$ in Figs 19 and 20. In both cases, yielding of the tension field and the subsequent loss of anchorage may be seen to correspond to the attainment of the peak load. A further comparison between the experimental and numerical results is shown in Fig. 21, where the inclination of the principal plane to the horizontal is shown for specimen I- $600 \times 200 \times 12 \times 4-1$. The following progression of behaviour may be observed from both the test and FE results: At the early stage of loading, the web panel is in the state of pure shear (i.e. the principal plane is inclined at $45^{\circ}$ to the horizontal); once the applied shear force exceeds the elastic shear buckling load, stresses along the tensile diagonal continue to increase while those along the compressive diagonal develop at a reduced rate, and hence the principal plane begins to rotate towards the horizontal; eventually the web panel yields under the combined stress field and an ultimate capacity is reached.

\subsection{Parametric studies}

Having achieved good overall agreement between the numerical and experimental results, a series of parametric studies were initiated to expand the available results over a wider range of plate girder web slendernesses and aspect ratios and to consider different end post conditions. The experimental results, together with the parametric study results, are then used to assess the general structural behaviour of lean duplex stainless steel plate girders and to investigate the applicability of the current codified design provisions. The generated models follow the basic assumptions stated in Section 3.1. The parametric studies covered three types of plate girders: (1) rigid end post plate girders of constant length, web height, flange width and flange thickness (similar to 
those employed in the experiments) but with varying web thickness to create a range of

web slendernesses $\bar{\lambda}_{\mathrm{w}}$ between 0.6 and 5.0, (2) rigid end post plate girders similar to (1) but with modified geometries to examine stocky cross-sections with web slendernesses ranging between 0.3 and 0.5 , and (3) non-rigid end post plate girders with the same cross-sectional dimensions as employed in case (1). The material properties adopted in the FE parametric studies were based on the average of the experimental material stressstrain curves from the seven tested plate thicknesses, which were $\mathrm{E}=206000 \mathrm{~N} / \mathrm{mm}^{2}$, $\sigma_{0.2}=500 \mathrm{~N} / \mathrm{mm}^{2}, \sigma_{1.0}=580 \mathrm{~N} / \mathrm{mm}^{2}, \mathrm{n}=10$ and $\mathrm{n}^{\prime}{ }_{0.2,1.0}=2.3$.

\section{Analysis of results}

\subsection{Introduction}

In this section, the results from the laboratory tests and the numerical analyses are examined and used to assess the applicability of the shear resistance design model given in Eurocode 3: Part 1.4 [15] to lean duplex stainless steel. Comparisons of the structural performance of lean duplex stainless steel plate girders with that of the more common austenitic and ferritic stainless steel grades are also made. Note that all comparisons have been carried out using the measured geometry and material properties, and with all partial factors set to unity.

\subsection{Failure modes}

Three different failure modes were identified from the experiments: (1) a shear dominant failure featuring shear buckling of the plate girder web, (2) a bending dominant failure featuring local buckling of the plate girder compression flange and (3) a combined bending plus shear failure, involving an interaction of failure modes (1) and (2). These three observed failure modes are discussed below.

\subsubsection{Shear dominant failure}

A shear dominant mode of failure was observed in test specimens I- $600 \times 200 \times 12 \times 4-1$, I- $600 \times 200 \times 12 \times 6-1, I-600 \times 200 \times 12 \times 4-2$ and I- $600 \times 200 \times 12 \times 6-2$ and many of the 
numerically generated results. A typical example of this mode of failure, obtained from plate girder I- $600 \times 200 \times 12 \times 4-1$, is shown in Fig. 22 . The moment-shear interaction diagram for this specimen, determined according to EN 1993-1-4 [15], is shown in Fig. 23, where $\mathrm{V}$ is the applied shear force, $\mathrm{V}_{\mathrm{b}, \mathrm{Rd}}$ is the shear buckling resistance of the cross-section including the flange contribution, $\mathrm{V}_{\mathrm{bw}, \mathrm{Rd}}$ is the shear buckling resistance of the web only, $\mathrm{M}$ is the applied moment, $\mathrm{M}_{\mathrm{c}, \mathrm{Rd}}$ is the cross-section bending resistance, $\mathrm{M}_{\mathrm{f}, \mathrm{Rd}}$ is the bending resistance of the flanges alone and for Class 4 cross-sections, $\mathrm{M}_{\mathrm{eff}, \mathrm{Rd}}$ is the bending resistance of the effective section. The location of the experimental data point (i.e. a high value of $\mathrm{V} / \mathrm{V}_{\mathrm{b}, \mathrm{Rd}}$ and a low value of $\mathrm{M} / \mathrm{M}_{\mathrm{c}, \mathrm{Rd}}$ ) clearly indicates that a shear dominant mode of failure would be anticipated.

\subsubsection{Bending dominant failure}

The second failure mode observed in the experimental and numerical analyses was a bending dominant mode involving local buckling of the compression flange. This mode of failure was observed in test specimens I- $600 \times 200 \times 12 \times 10-1$, I- $600 \times 200 \times 12 \times 10-2$ and $\mathrm{I}-600 \times 200 \times 15 \times 15-2$ and a number of the numerically generated results. A typical example, obtained for specimen I- $600 \times 200 \times 12 \times 10-2$, is presented in Fig. 24. The moment-shear interaction diagram from EN 1993-1-4 [15] for this plate girder (see Fig. 25) reveals a high value of $M / M_{c, R d}$ and lower value of $V / V_{b, R d}$, and hence anticipates a bending dominant failure.

\subsubsection{Combined bending plus shear failure}

An intermediate failure mode involving an interaction of shear and bending and a combination of the features described in Sections 4.2.1 and 4.2.2 was observed in test specimens I- $600 \times 200 \times 12 \times 8-1$ and I- $600 \times 200 \times 12 \times 8-2$ and some of the numerical models. This mode of failure is shown in Fig. 26 for plate girder I- $600 \times 200 \times 12 \times 8-1$ where both flange and web deformation may be observed. The moment-shear interaction diagram from EN 1993-1-4 [15] for this specimen is given in Fig. 27 where the shear and moment utilisations indicate that a combined shear plus bending failure mode would be expected.

\subsection{Eurocode 3: Part 1.4 design method}


The design approach adopted in the European pre-Standard ENV 1993-1-4 (2006) [28] for determining the shear resistance of stainless steel plate girders was based on the simple post critical method of ENV 1993-1-1 (1992) [29] which was developed by Dubas [30] based on Höglund's [31, 32] rotated stress field theory ignoring any flange contribution. The development of the shear buckling provisions given in ENV 1993-14 [28] considered the only experiments featuring shear buckling of stainless steel sections that were available at the time, which were those of Carvalho et al. [33].

The simple post critical method was later found by Olsson [11] to be rather conservative, and following an experimental and numerical study of a series of stainless steel plate girders, an improved design approach was proposed. Olsson's [11] proposal was based on Höglund's [31, 32] rotated stress field method taking into consideration both the web and the flange contributions to the resistance to shear buckling, but ignoring the effect of the end post; this approach was adopted in the final version of EN 1993-1-4 (2006) [15]. The ultimate shear buckling resistance $\mathrm{V}_{\mathrm{b}, \mathrm{Rd}}$ of stainless steel plate girders according to EN 1993-1-4 [15] is expressed similarly to that of carbon steel plate girders in EN 1993-1-5 [21], as given by Eq. (4), but with modified web and flange contributions, $\mathrm{V}_{\mathrm{bw}, \mathrm{Rd}}$ and $\mathrm{V}_{\mathrm{bf}, \mathrm{Rd}}$, respectively.

$$
\mathrm{V}_{\mathrm{b}, \mathrm{Rd}}=\mathrm{V}_{\mathrm{bw}, \mathrm{Rd}}+\mathrm{V}_{\mathrm{bf}, \mathrm{Rd}} \leq \frac{\eta \mathrm{f}_{\mathrm{yw}} \mathrm{h}_{\mathrm{w}} \mathrm{t}_{\mathrm{w}}}{\sqrt{3} \gamma_{\mathrm{M} 1}}
$$

where $\eta$ is equal to $1.2, f_{y w}$ is the yield strength of the web, $h_{w}$ is the depth of the web, $t_{\mathrm{w}}$ is the thickness of the web and $\gamma_{\mathrm{M} 1}$ is the shear partial factor. The web contribution is given by:

$$
\mathrm{V}_{\mathrm{bw}, \mathrm{Rd}}=\frac{\chi_{\mathrm{w}} \mathrm{f}_{\mathrm{yw}} \mathrm{h}_{\mathrm{w}} \mathrm{t}_{\mathrm{w}}}{\sqrt{3} \gamma_{\mathrm{M} 1}}
$$

in which $\chi_{w}$ is the reduction factor for web buckling, and the flange contribution is given by:

$$
\mathrm{V}_{\mathrm{bf}, \mathrm{Rd}}=\left(\frac{\mathrm{b}_{\mathrm{f}} \mathrm{t}_{\mathrm{f}}{ }^{2} \mathrm{f}_{\mathrm{yf}}}{\mathrm{c} \gamma_{\mathrm{M} 1}}\right)\left(1-\left(\frac{\mathrm{M}_{\mathrm{Ed}}}{\mathrm{M}_{\mathrm{f}, \mathrm{Rd}}}\right)^{2}\right)
$$

with the distance c given by Eq. (7): 
$\mathrm{c}=\left(0.17+\frac{3.5 \mathrm{~b}_{\mathrm{f}} \mathrm{t}_{\mathrm{f}}{ }^{2} \mathrm{f}_{\mathrm{yf}}}{\mathrm{t}_{\mathrm{w}} \mathrm{h}_{\mathrm{w}}{ }^{2} \mathrm{f}_{\mathrm{yw}}}\right) \mathrm{a}$ with $\frac{\mathrm{c}}{\mathrm{a}} \leq 0.65$

where $b_{f}$ is the flange width, $t_{f}$ is the flange thickness, $f_{y f}$ is the yield strength of the flange, $\mathrm{M}_{\mathrm{Ed}}$ is the design bending moment, $\mathrm{M}_{\mathrm{f}, \mathrm{Rd}}$ is the design plastic moment of resistance of a cross-section consisting of the flanges only and a is the shear panel length.

\subsection{Comparison of test and numerical shear capacities with EN 1993-1-4 for plate girders with rigid end posts}

A comparison between the ultimate capacity achieved by the test specimens, all of which had rigid end posts, and the predicted capacity according to EN 1993-1-4 [15], assuming proportional loading (i.e. the ratio of shear force to bending moment remains constant), is presented in Table 5. In the EN 1993-1-4 [15] calculation, due allowance for the reduced flanged contribution to the shear resistance owing to the coexistent bending moment has been made in accordance with Eq. (6). The comparisons show that the test results consistently lie above the codified predictions, with a mean ratio of test to EN 1993-1-4 capacity of 1.38 and a coefficient of variation (COV) of 0.07. A similar trend may be seen when the parametric FE results for the plate girders with rigid end posts are compared to the codified predictions in Table 6 , with a mean ratio of test to EN 1993-1-4 capacity of 1.35 and a COV of 0.15 .

For specimens exhibiting a shear dominant failure mode, defined as those where the ratio of shear force to bending moment in the test $V_{u, \text { test }} / M_{u, \text { test }}>V_{b w, R d} / M_{f, R d}$ (see Fig. 28), a comparison between the test and FE results is also plotted with the EN 1993-1-4 [15] design model in Fig. 29. This comparison is presented in terms of shear buckling reduction factor $\chi_{\mathrm{w}}$ versus web slenderness $\bar{\lambda}_{\mathrm{w}}$. In locating the test and FE data points, the flange contribution calculated according to Eq. (6), has been deducted from the test ultimate shear resistance, and the result has been normalised by the yield capacity of the web in shear. The high normalised shear capacities (beyond yield and indeed beyond 1.2 times yield) obtained at low slendernesses are attributed to strain hardening. 


\subsection{Comparison of test and numerical shear capacities with EN 1993-1-4 for plate girders with non-rigid end posts}

The current shear design provisions in EN 1993-1-4 [15] do not differentiate between plate girders with rigid and non-rigid end posts. For carbon steel plate girders, EN 1993$1-5$ [21] does distinguish between rigid and non-rigid end posts for web slenderness

values $\bar{\lambda}_{\mathrm{w}}>1.08$ and Estrada et al. [34] reported a clear distinction in response between the two cases, particularly for higher web slendernesses and low panel aspect ratios.

Following the successful validation of the numerical models against the test results reported in this paper on plate girders with rigid end posts, parametric studies on plate girders with non-rigid end posts were performed. The results are shown in Fig. 29 and in Table 7, where a mean ratio of test to EN 1993-1-4 capacity of 1.30 and a COV of 0.09 was found. A comparison of the ultimate shear resistances obtained from the FE models with rigid and non-rigid end posts (but otherwise similar geometry) is presented in Table 8, where a mean $\mathrm{V}_{\mathrm{u}, \mathrm{FE}} / \mathrm{V}_{\mathrm{u}, \mathrm{FE} \text {,non-rigid }}$ of 1.05 and a COV of 0.05 was found. An increase in shear resistance up to $18 \%$ may be observed when rigid end posts are employed. As observed by Estrada et al. [34], the differences are greatest for higher web slendernesses and lower web panel aspect ratios.

\subsection{Comparison with other stainless steel grades}

The results obtained from the tests carried out in the present study on lean duplex stainless plate girders are compared to existing test results from Olsson [11], Real et al. [12] and Estrada et al. [13] on austenitic and duplex stainless steel plate girders in Fig. 30. Upon examination of the results, the following conclusions can be drawn: firstly, for similar values of slenderness the results from the lean duplex plate girders exhibit similar normalized performance to equivalent plate girders of other stainless steel grades; secondly, the collected test data show that the Eurocode 3: Part 1.4 [15] shear resistance design model can be safely applied to all stainless steel grades, but improved efficiency could be achieved by re-examining the design model and differentiating between rigid and non-rigid end posts. 


\section{Summary and conclusions}

An experimental study into the structural performance of lean duplex stainless steel plate girders has been reported in this paper. The results of the experimental investigation were supplemented by means of a parallel numerical study. The numerical models were initially validated against the experimental results and subsequently used to conduct parametric studies to investigate a wider range of plate girder geometries. Based on the results from both the experiments and the FE simulations, the obtained modes of failure were discussed and the shear design provisions of EN 1993-1-4 were assessed. Three different modes of failure were observed: a shear dominant failure, a bending dominant failure and a combined bending plus shear failure. It was found that the current Eurocode 3: Part 1.4 design equations are safely applicable to lean duplex stainless steel, but improved efficiency could be achieved through a revised design model and making distinction between plate girders with rigid and non-rigid end posts. Comparisons of the results obtained herein with others collected from the literature showed that this conclusion was also applicable to other stainless steel grades. Further research on this topic is underway.

\section{ACKNOWLEDGMENTS}

The authors would like to thank the UK Outokumpu Stainless Steel Research Foundation for the fabrication and supply of test specimens and for funding the laboratory testing programme.

\section{References}

[1] Gardner, L. (2005). The use of stainless steel in structures. Progress in Structural Engineering and Materials. 7(2), 45-55. 
[2] Gardner, L., Insausti, A., Ng, K. T. and Ashraf, M. (2010). Elevated temperature material properties of stainless steel alloys. Engineering Structures. 66(5), 634-647.

[3] Nilsson, J. O., Chai, G. and Kivisäkk, U. (2008). Recent development of stainless steels, Proceedings of the Sixth European Stainless steel Conference, 10-13 June 2008. 585-590. Helsinki, Finland.

[4] Sieurin, H., Sandström, R. and Westin, E.M. (2007). Fracture toughness of the lean duplex stainless steel LDX 2101. Metallurgical and Materials Transactions A, 37(10), 2975-2981.

[5] EN 10088-4. (2009). Stainless steels - Part 4: Technical delivery conditions for sheet/plate and strip of corrosion resisting steels for general purposes. CEN.

[6] Theofanous, M. and Gardner, L. (2009). Testing and numerical modelling of lean duplex stainless steel hollow section columns. Engineering Structures. 31(12), 30473058 .

[7] Theofanous, M. and Gardner, L. (2010). Experimental and numerical studies of lean duplex stainless steel beams. Journal of Constructional Steel Research. 66(6), 816-825.

[8] Saliba, N. and Gardner, L. (2012). Cross-section stability of lean duplex stainless steel welded I-sections. Journal of Constructional Steel Research. (submitted).

[9] Huang, Y., and Young, B. (2012). Material properties of cold-formed lean duplex stainless steel sections. Thin-walled structures. 54, 72-81.

[10] Patton, M., and Singh, K. (2012). Numerical modelling of lean duplex stainless steel hollow columns of square, $\mathrm{L}-, \mathrm{T}-$, and +- shaped cross sections under pure axial compression. Thin-walled structures. 53, 1-8. 
[11] Olsson, A. (2001). Stainless steel plasticity-material modelling and structural applications. PhD Thesis. Lulea University of Technology, Sweden.

[12] Real, E., Mirambell, E., and Estrada, I. (2007). Shear response of stainless steel plate girders. Engineering Structures. 29(7), 1626-1640.

[13] Estrada, I., Real, E., and Mirambell, E. (2007). General behaviour and effect of rigid and non-rigid end post in stainless steel plate girders loaded in shear. Part I: Experimental study. Journal of Constructional Steel Research. 63 (7), 970-984.

[14] Hassanein, M. (2011). Finite element investigation of shear failure of lean duplex stainless steel plate girders. Thin-walled structures. 49(8), 964-973.

[15] EN 1993-1-4. (2006). Eurocode 3: Design of steel structures - Part 1.4: General rules - Supplementary rules for stainless steel. CEN.

[16] EN 10002-1. (2001). Metallic materials-Tensile testing, Part 1: Method of test at ambient temperature. CEN.

[17] Mirambell, E. and Real, E. (2000). On the calculation of deflections in structural stainless steel beams: an experimental and numerical investigation. Journal of Constructional Steel Research. 54(1), 109-133.

[18] Rasmussen, K.J.R. (2003). Full-range stress-strain curves for stainless steel alloys. Journal of Constructional Steel Research. 59(1), 47-61.

[19] Gardner, L. and Ashraf, M. (2006). Structural design for non-linear metallic materials. Engineering Structures. 28(6), 926-934.

[20] EN 12072. (2000). Welding consumables - Wire electrodes, wires and rods for arc welding of stainless and heat-resisting steels - Classification. BSI. 
[21] EN 1993-1-5. (2006). Eurocode 3: Design of steel structures - Part 1.5: Plated structural elements. CEN.

[22] Hibbitt, Karlsson \& Sorensen, Inc. (2010). ABAQUS. ABAQUS/Standard user's manual volumes I-III and ABAQUS CAE manual. Version 6.10. (Pawtucket, USA).

[23] Ellobody, E. and Young, B. (2005). Structural performance of cold-formed high strength stainless steel columns. Journal of Constructional Steel Research. 61(12), 1631-1649.

[24] Lecce, M. and Rasmussen, K. J. R. (2006). Distortional buckling of cold-formed stainless steel sections: Finite-element modelling and design. Journal of Structural Engineering, ASCE. 132(4), 505-514.

[25] Dawson, R.G. and Walker, A.C. (1972). Post-buckling of geometrically imperfect plates. Journal of the Structural Division, ASCE. 98(1), 75-94.

[26] Gardner, L. and Nethercot, D.A. (2004). Numerical modeling of stainless steel structural components-A consistent approach. Journal of Structural Engineering, ASCE. 130(10), 1586-1601.

[27] Ashraf, M., Gardner, L. and Nethercot, D.A. (2006). Finite element modelling of structural stainless steel cross-sections. Thin-walled structures. 44(10), 1048-1062.

[28] ENV 1993-1-4. (1996). Eurocode 3: Design of steel structures - Part 1.4: General rules - Supplementary rules for stainless steels. CEN.

[29] ENV 1993-1-1. (1992). Eurocode 3: Design of steel structures - Part 1.1: General rules and rules for buildings. CEN.

[30] Dubas, P. (1980). Reflexions sur certains problems de seurite et stabilite en construction metallique. Memoires CERES. (55). Liege, Belgium. 
[31] Höglund, T. (1971). Behaviour and strength of the web of thin plate I-girders. Bulletin No. 93, Division of building statics and structural engineering. The Royal Institute of Technology, Stockholm, Sweden.

[32] Höglund, T. (1973). Design of thin plate I girders in shear and bending with special reference to web buckling. Bulletin No. 94, Division of building statics and structural engineering. Royal Institute of Technology, Stockholm, Sweden.

[33] Carvalho, E. C. G., Van den Berg, G. J. and Van der Merwe, P. (1990). Local shear buckling in cold-formed stainless steel beam webs. Proceedings of the annual technical session, stability of bridges. Structural Stability Research Council. April 10-11. St Louis, Missouri, USA.

[34] Estrada, I., Real, E., and Mirambell, E. (2007). General behaviour and effect of rigid and non-rigid end post in stainless steel plate girders loaded in shear. Part II: Extended numerical study and design proposal. Journal of Constructional Steel Research. 63(7), 985-996. 


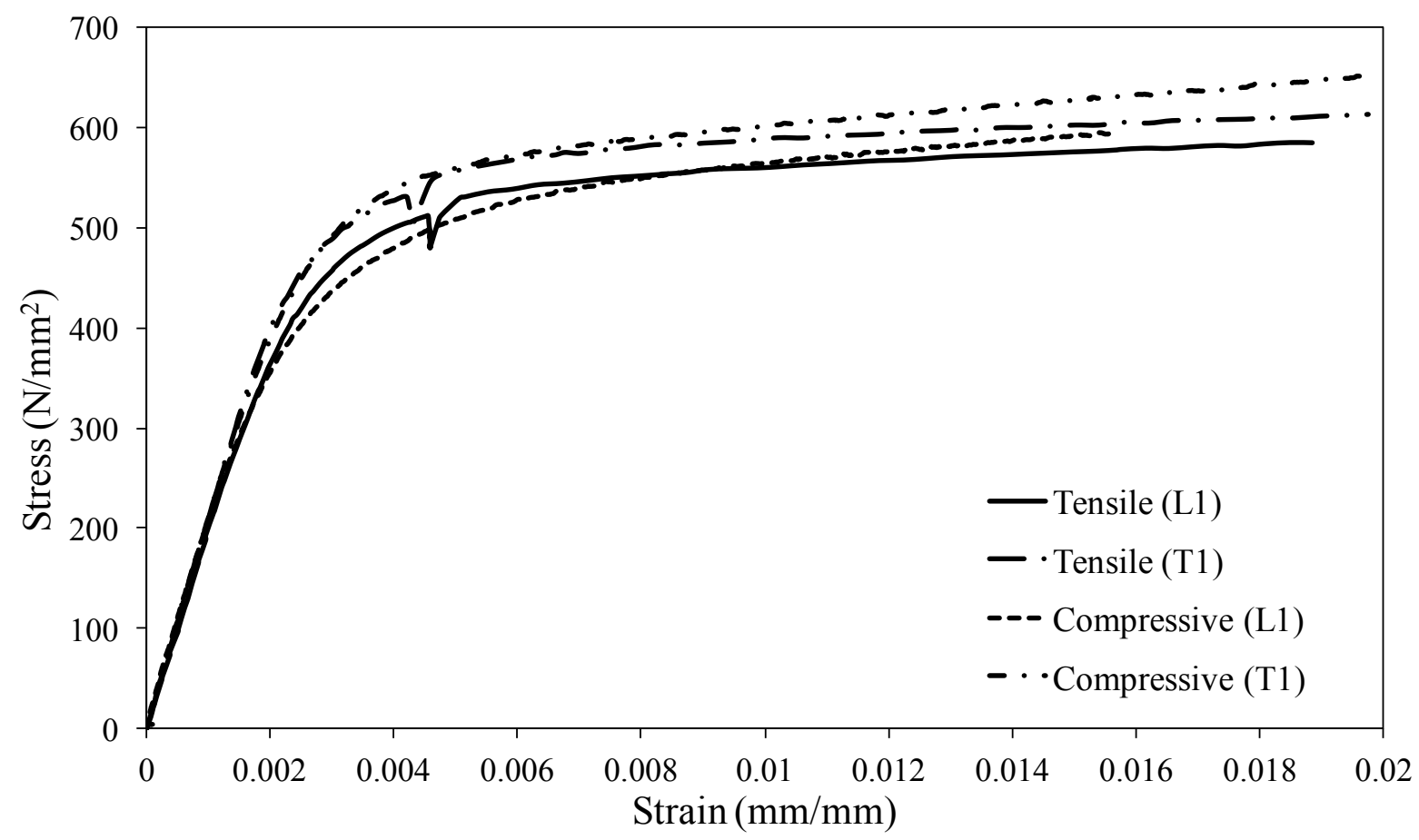

Fig. 1: Initial part of tensile and compressive stress-strain curves for $4 \mathrm{~mm}$ material $(\mathrm{L}=$ Longitudinal, T: Transverse).

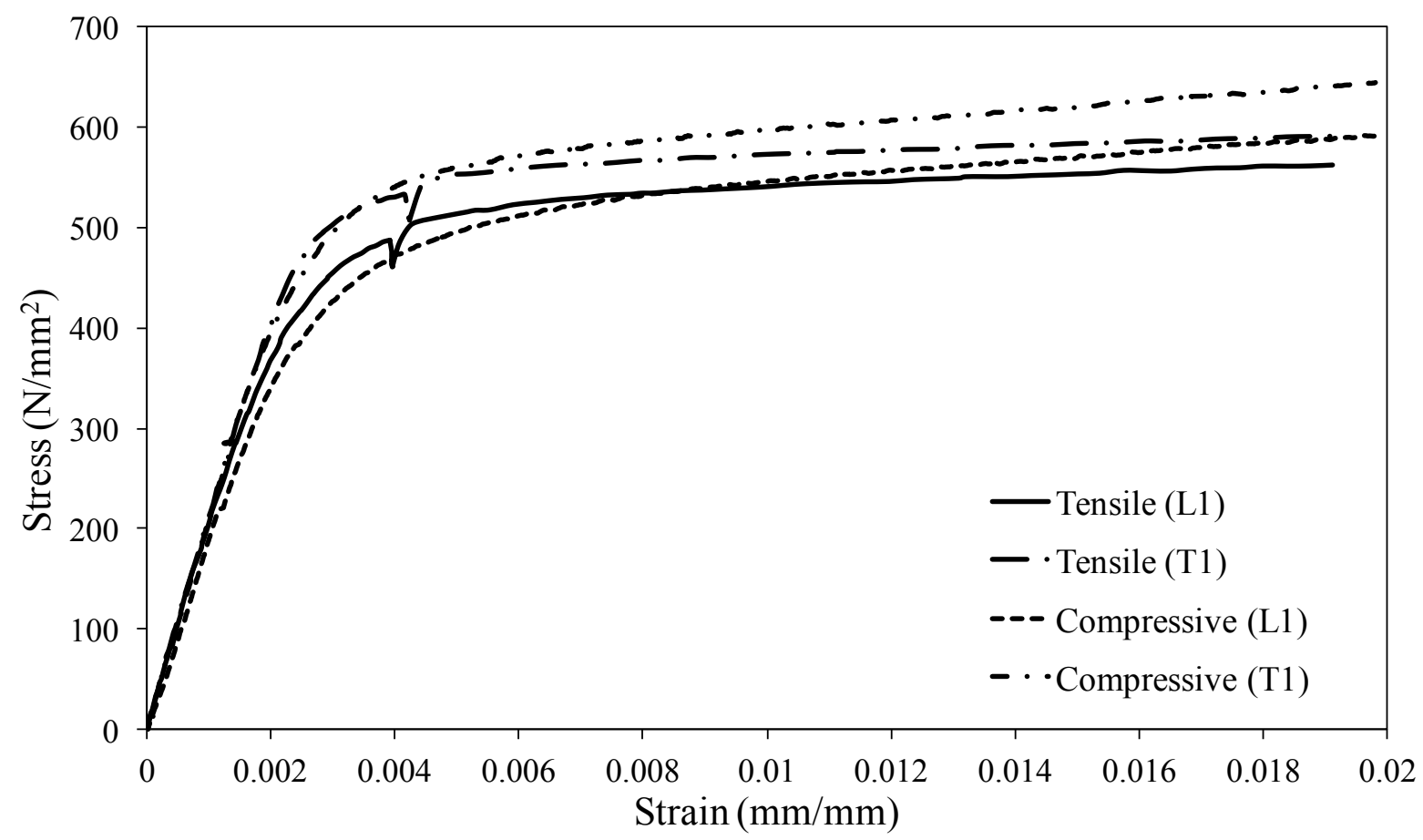

Fig. 2: Initial part of tensile and compressive stress-strain curves for $6 \mathrm{~mm}$ material $(\mathrm{L}=$ Longitudinal, T: Transverse). 


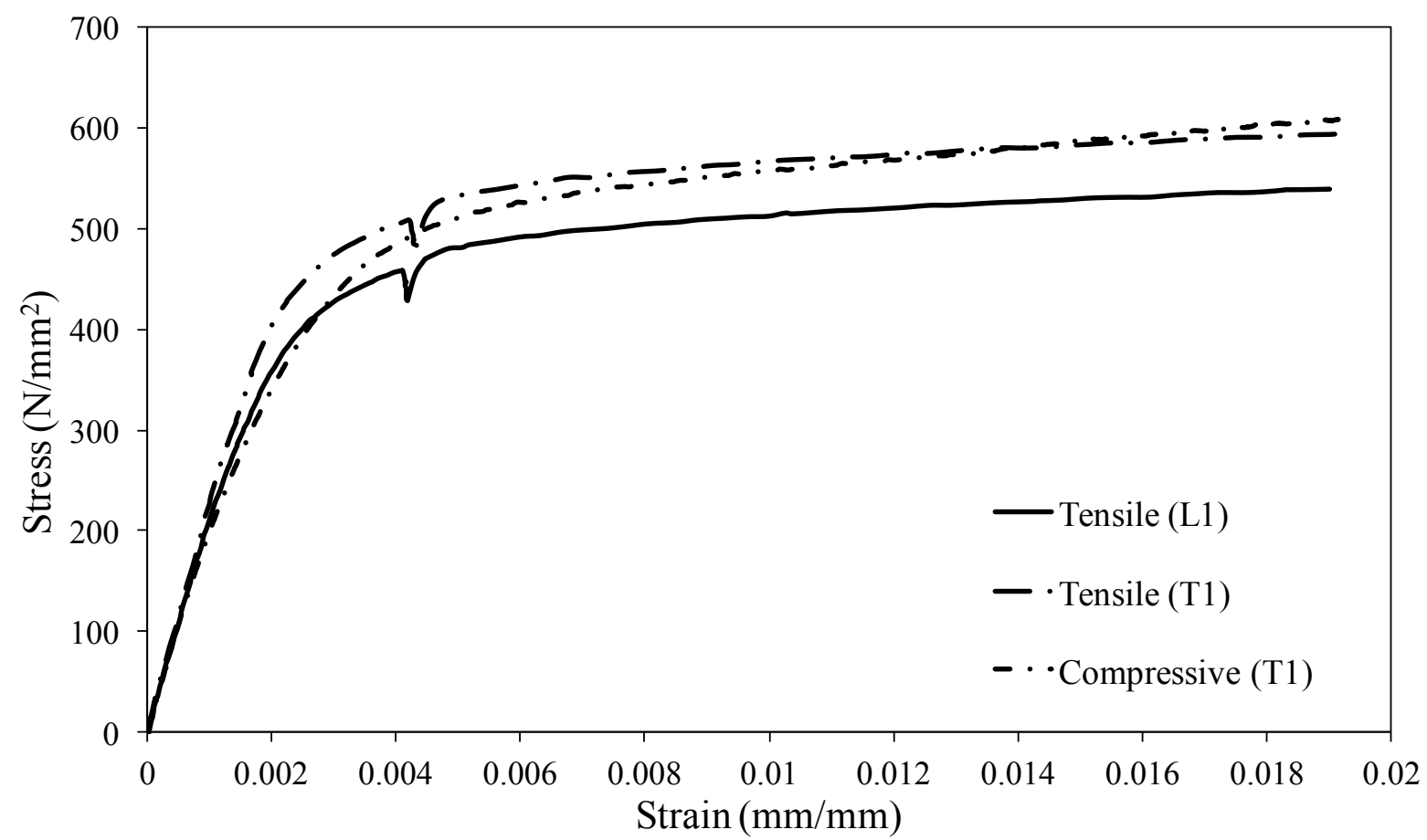

Fig. 3: Initial part of tensile and compressive stress-strain curves for $8 \mathrm{~mm}$ material $(\mathrm{L}=$ Longitudinal, T: Transverse).

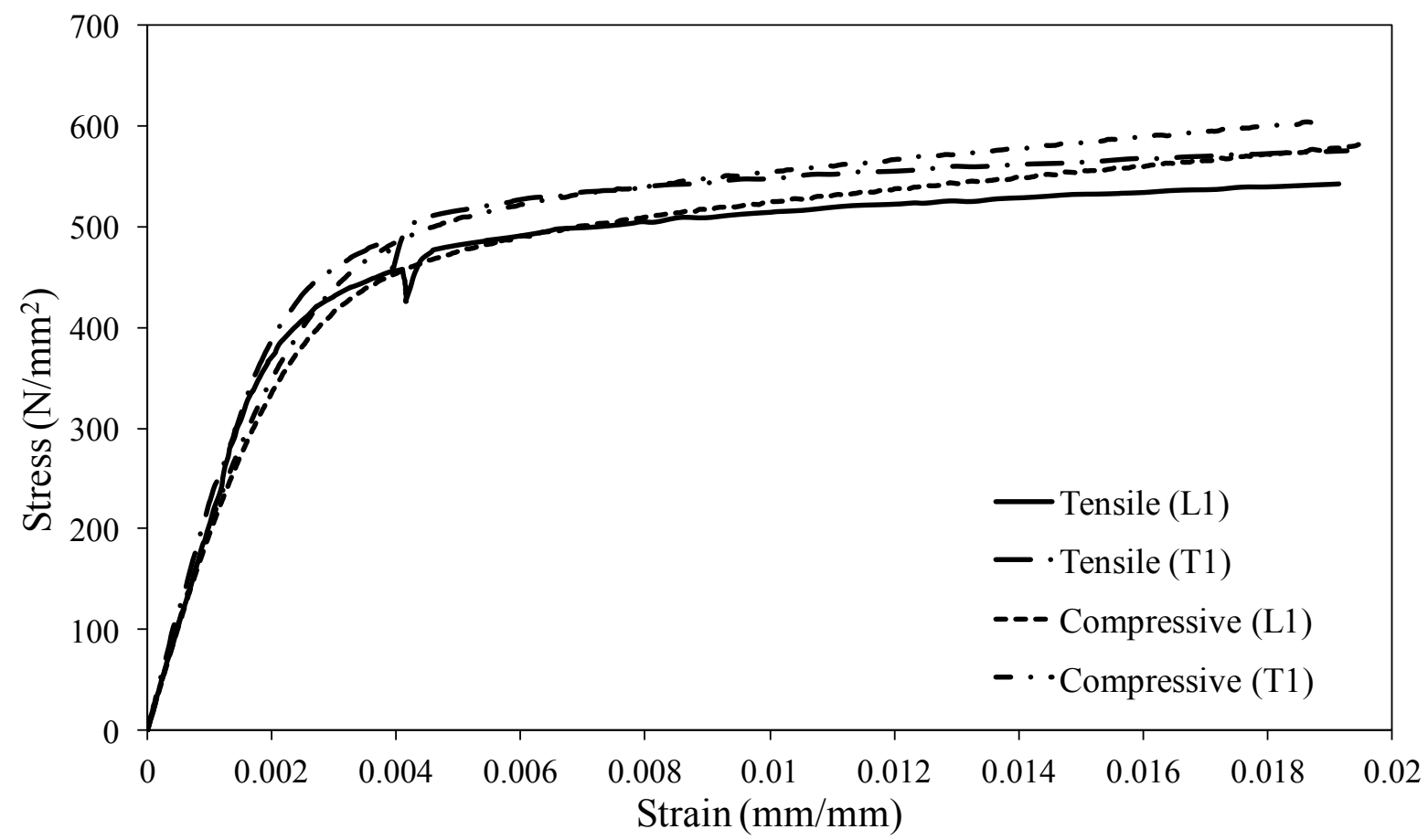

Fig. 4: Initial part of tensile and compressive stress-strain curves for $10 \mathrm{~mm}$ material $(\mathrm{L}=$ Longitudinal, $\mathrm{T}=$ Transverse). 


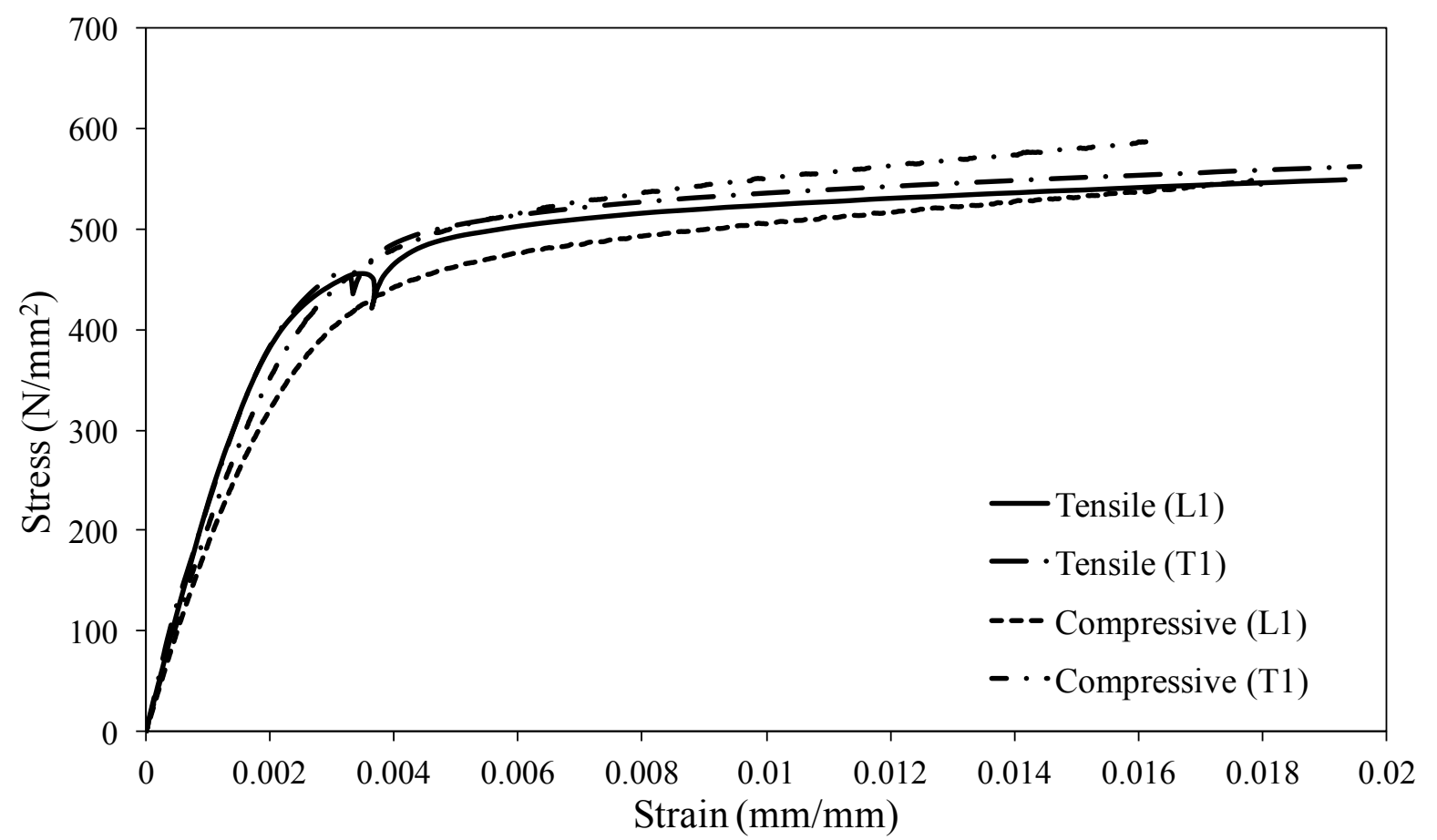

Fig. 5: Initial part of tensile and compressive stress-strain curves for $12 \mathrm{~mm}$ material ( $\mathrm{L}=$ Longitudinal, $\mathrm{T}=$ Transverse).

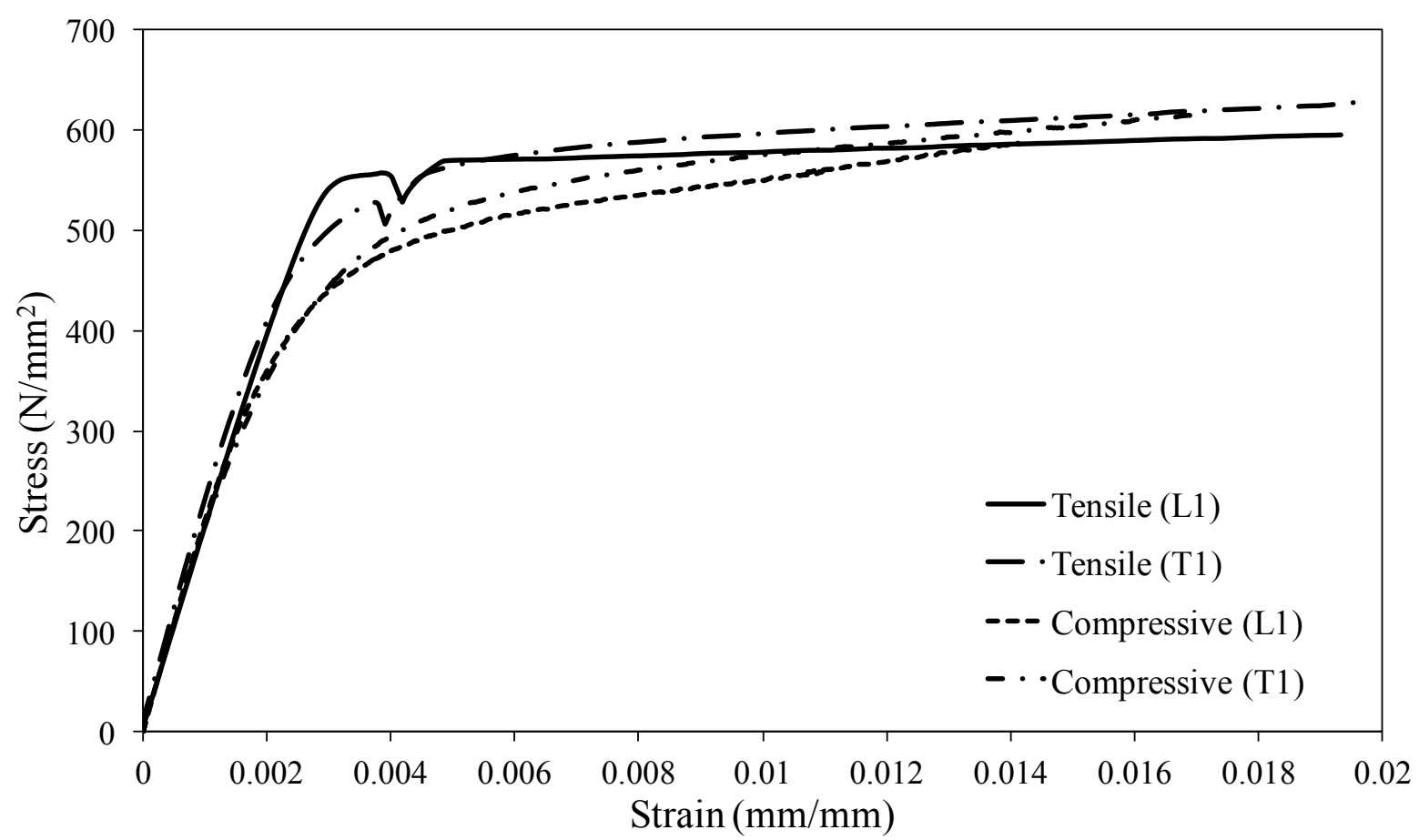

Fig. 6: Initial part of tensile and compressive stress-strain curves for $15 \mathrm{~mm}$ material ( $\mathrm{L}=$ Longitudinal, $\mathrm{T}=$ Transverse). 


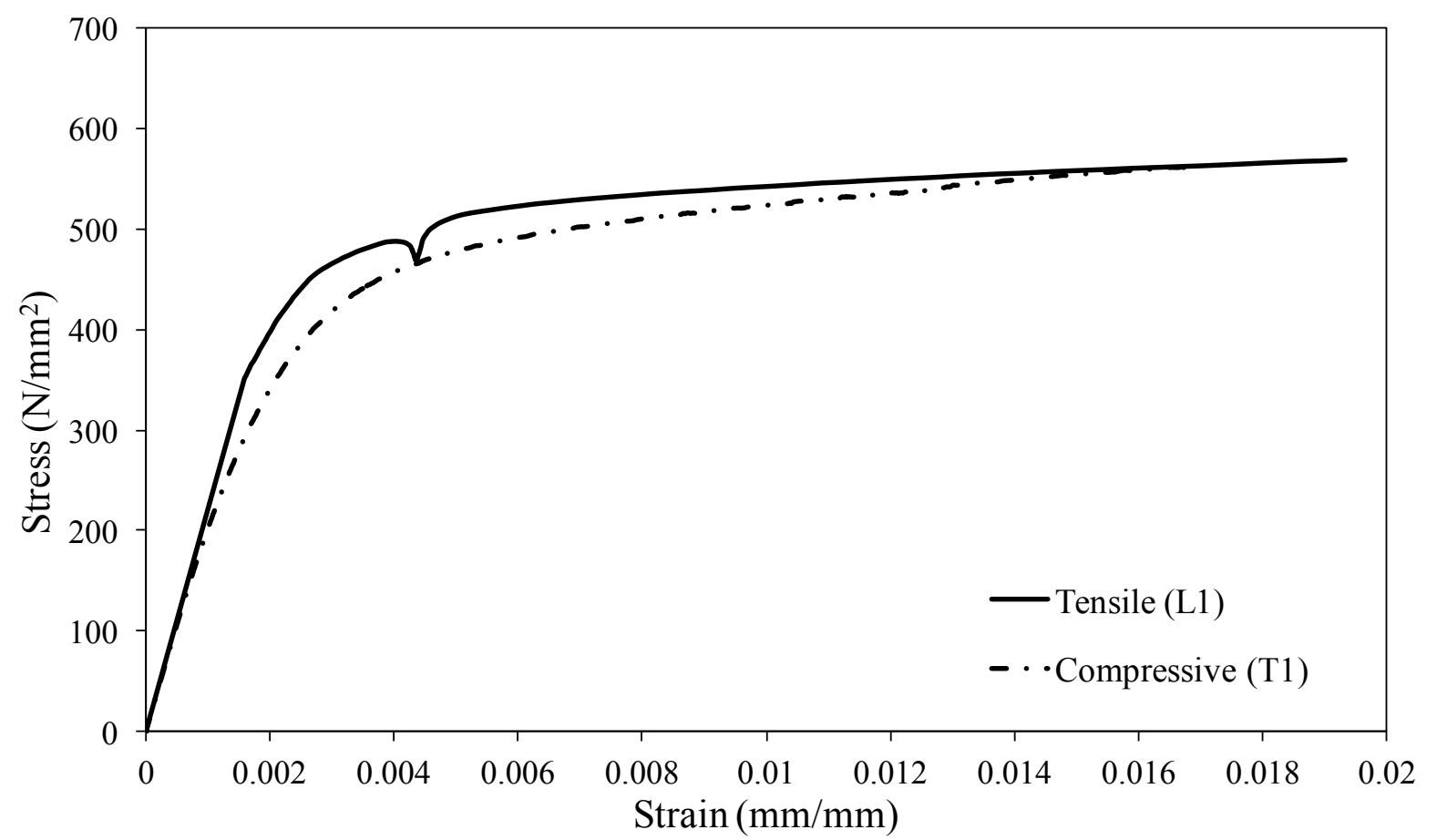

Fig. 7: Initial part of tensile and compressive stress-strain curves for $20 \mathrm{~mm}$ material $(\mathrm{L}=$ Longitudinal, $\mathrm{T}=$ Transverse).
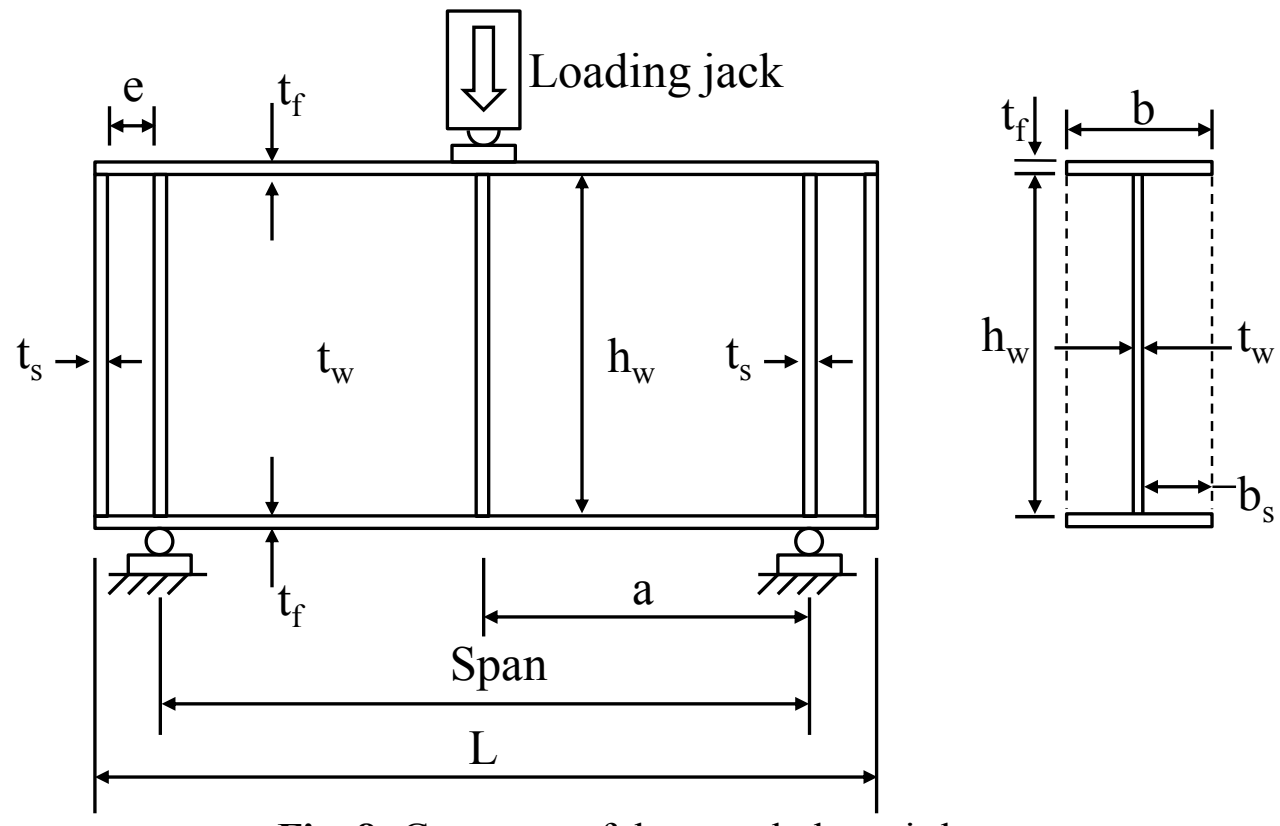

Fig. 8: Geometry of the tested plate girders. 


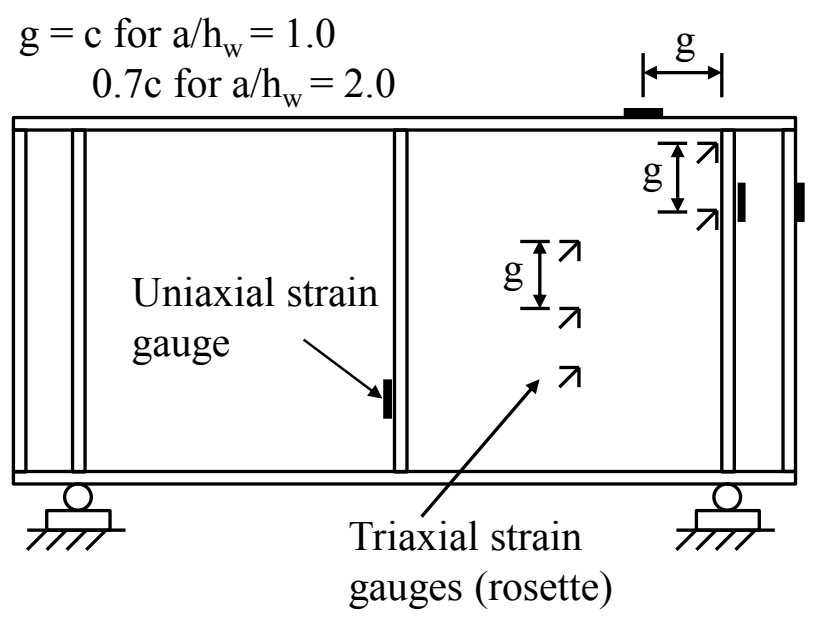

Fig. 9: Location of strain gauges.

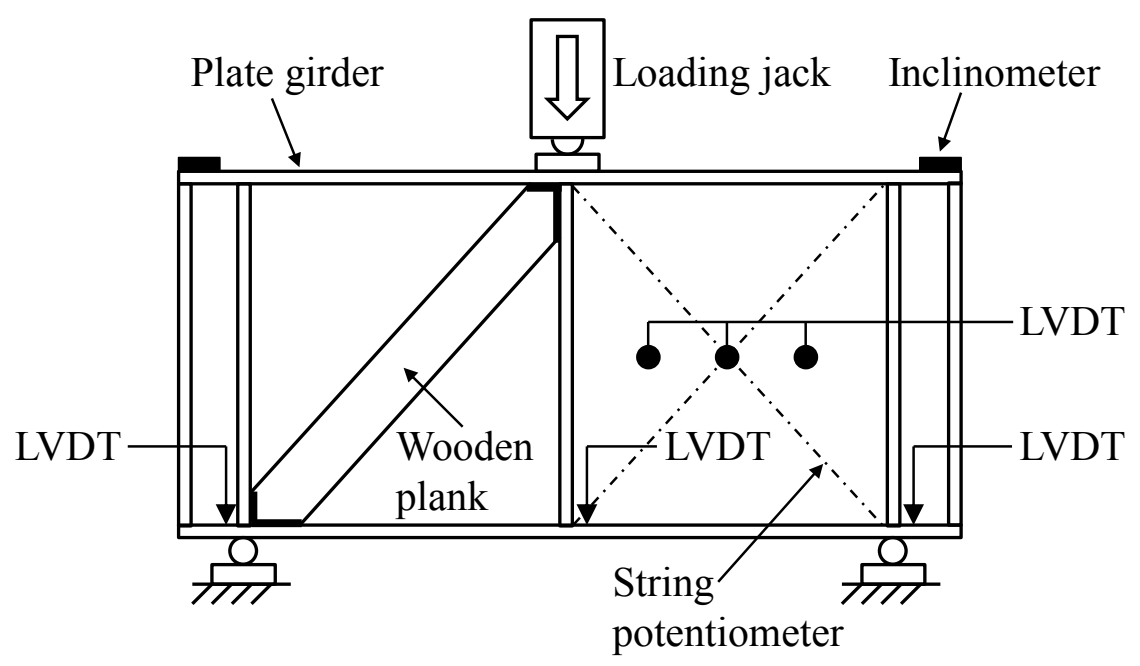

Fig. 10: Schematic shear test setup and instrumentation. 


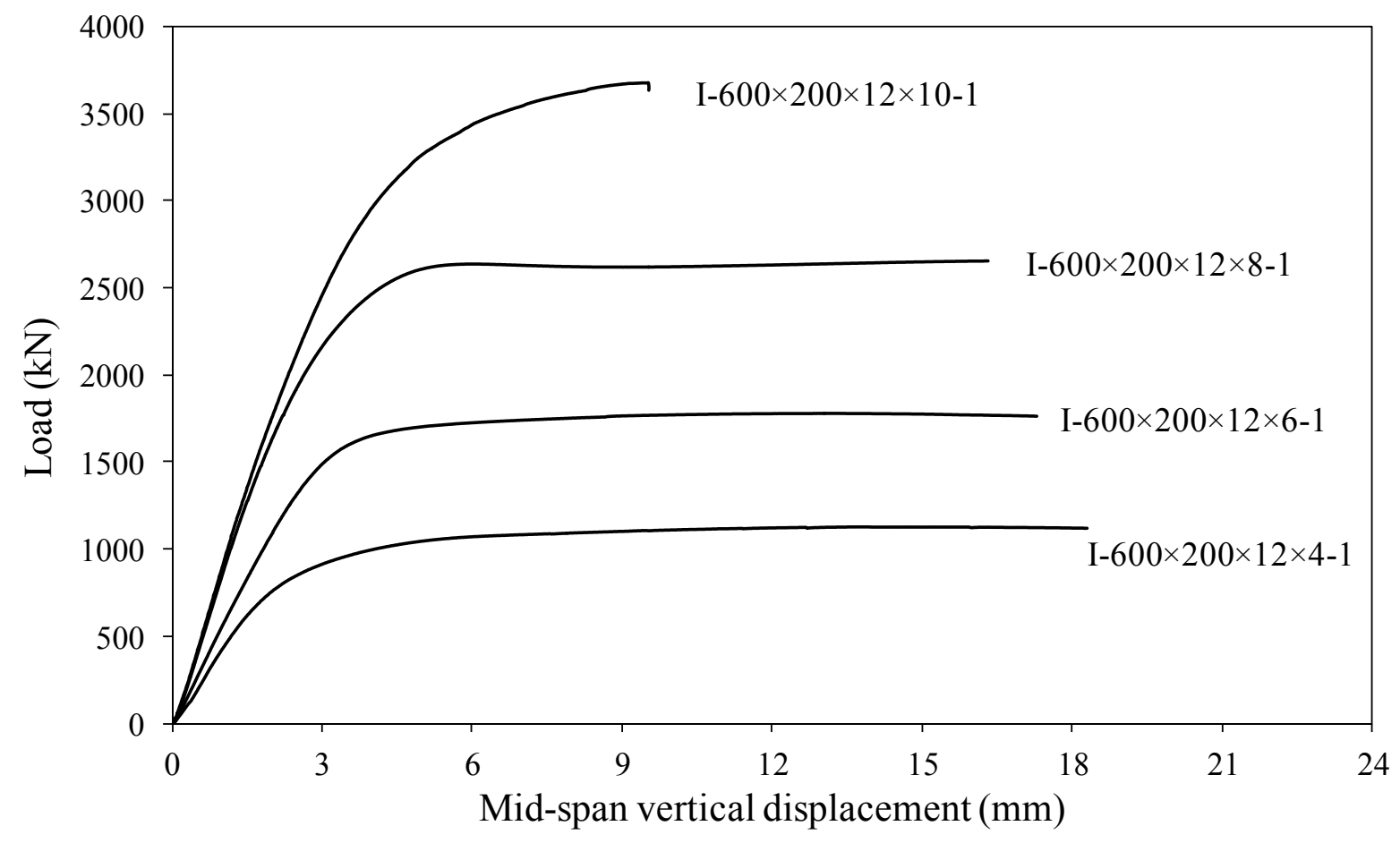

Fig. 11: Load-mid-span vertical displacement curves for plate girders of aspect ratio 1.0.

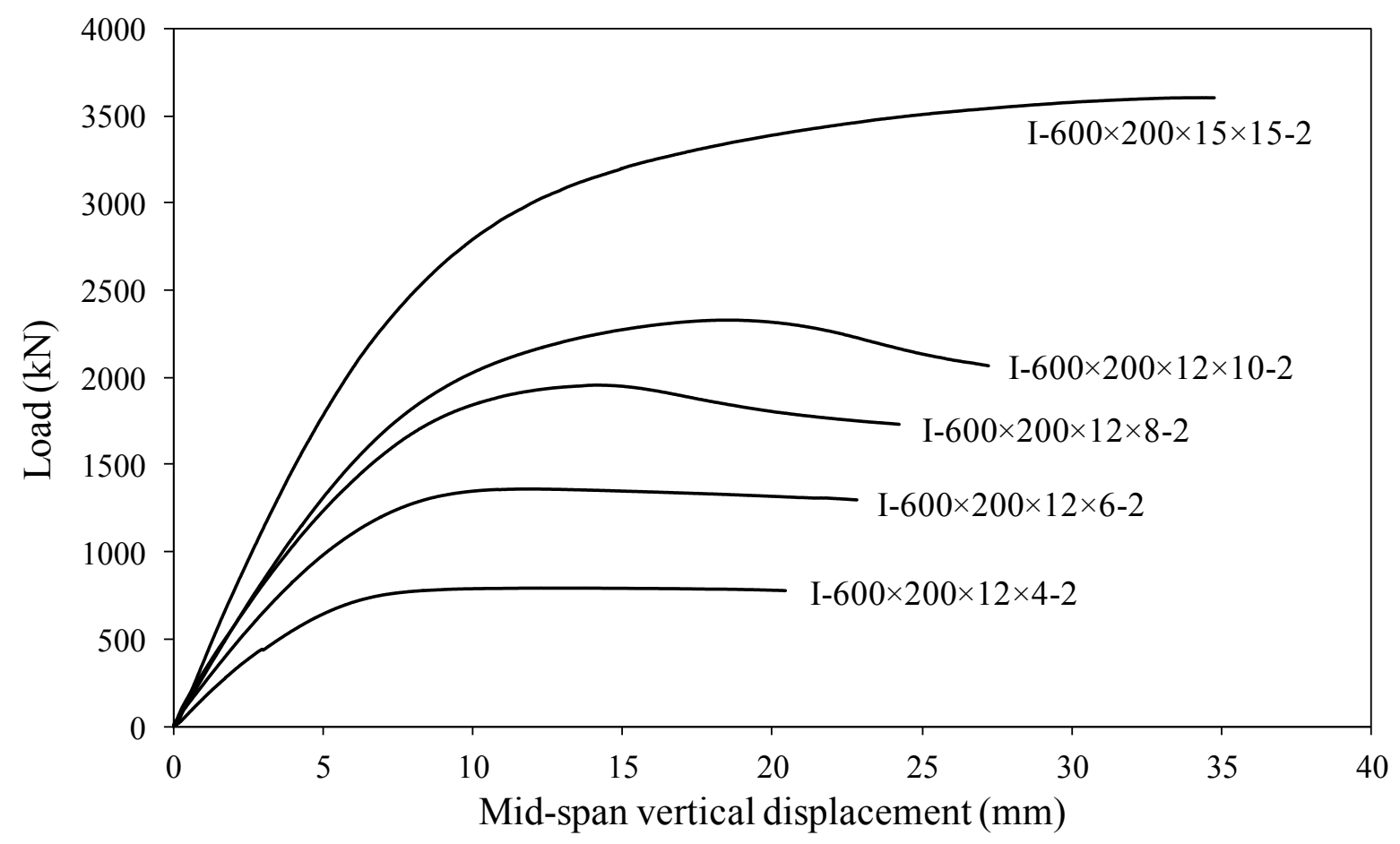

Fig. 12: Load-mid-span vertical displacement curves for plate girders of aspect ratio 2.0. 


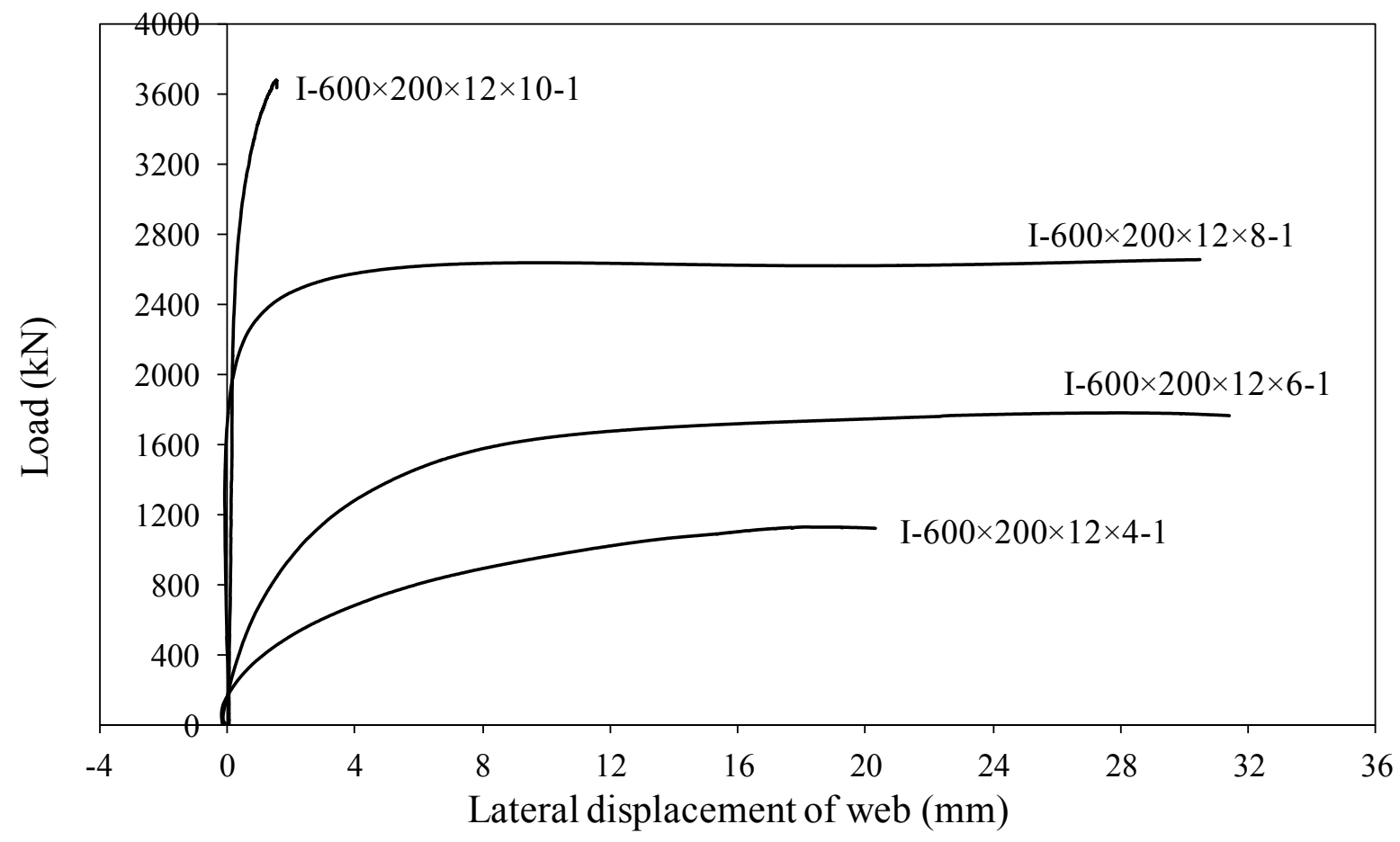

Fig. 13: Load-lateral web displacement curves for plate girders of aspect ratio 1.0.

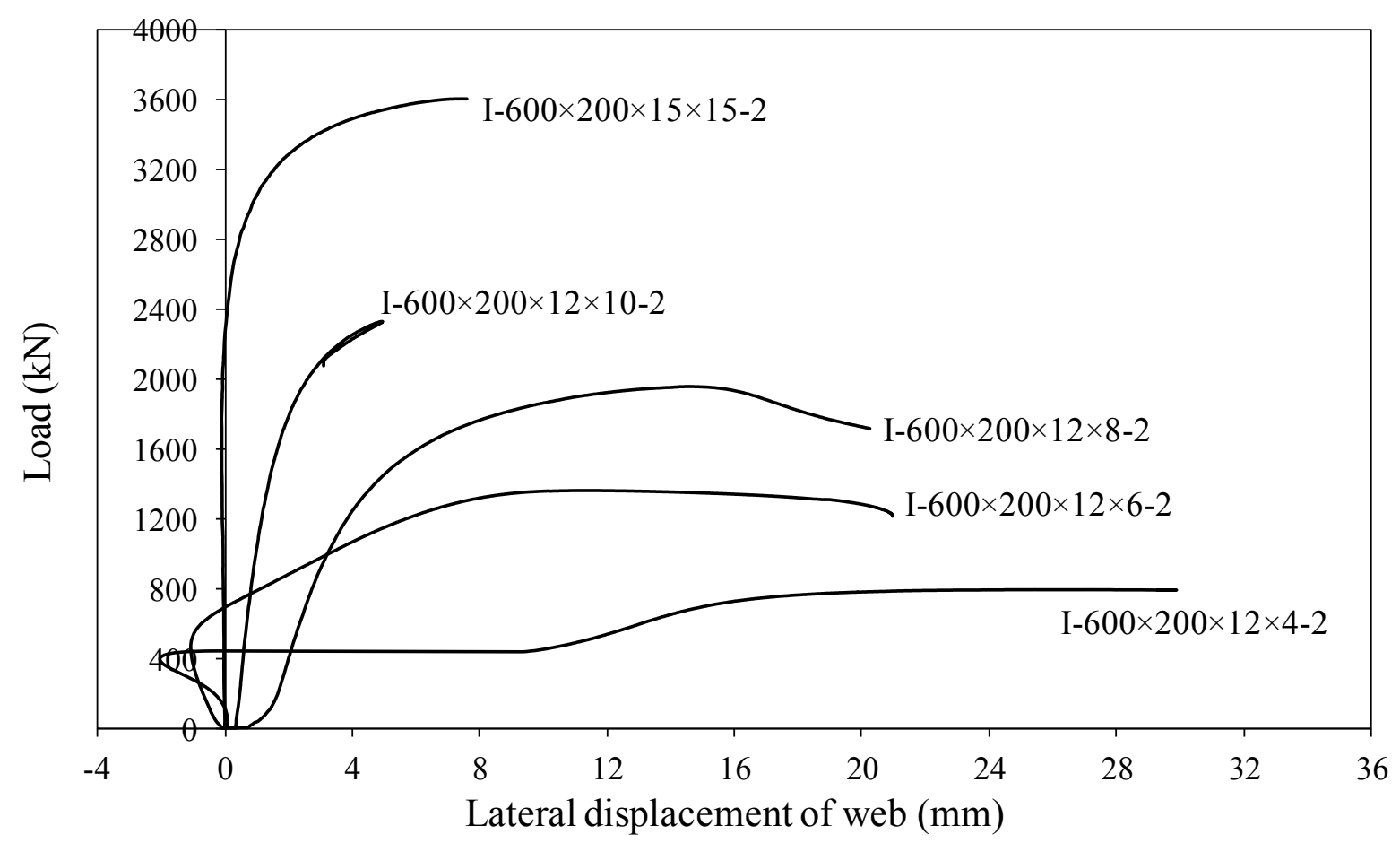

Fig. 14: Load-lateral web displacement curves for plate girders of aspect ratio 2.0. 


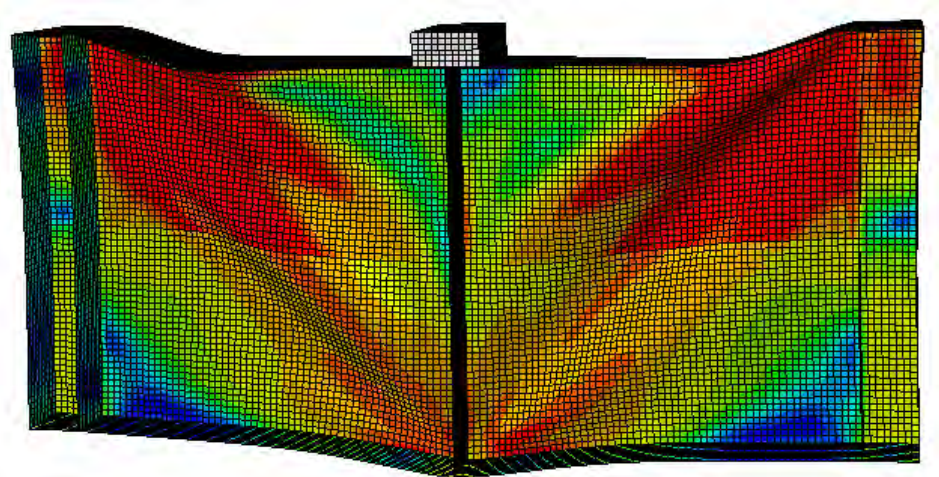

Fig. 15: Typical shear dominant FE failure mode for plate girders with a web panel aspect ratio of 1.0 .

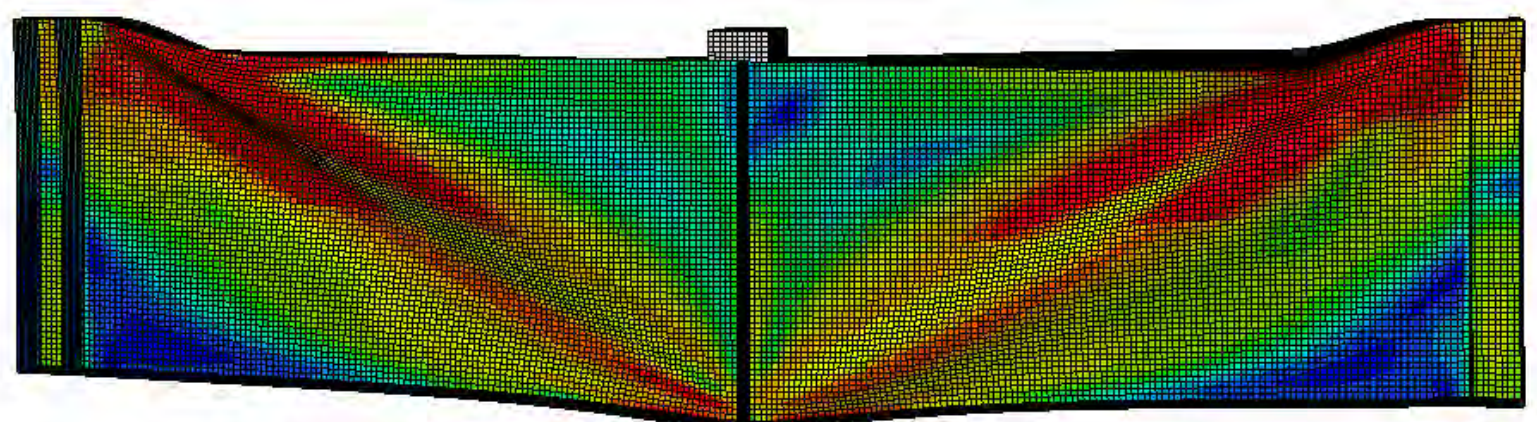

Fig. 16: Typical shear dominant FE failure mode for plate girders with a web panel aspect ratio of 2.0 . 


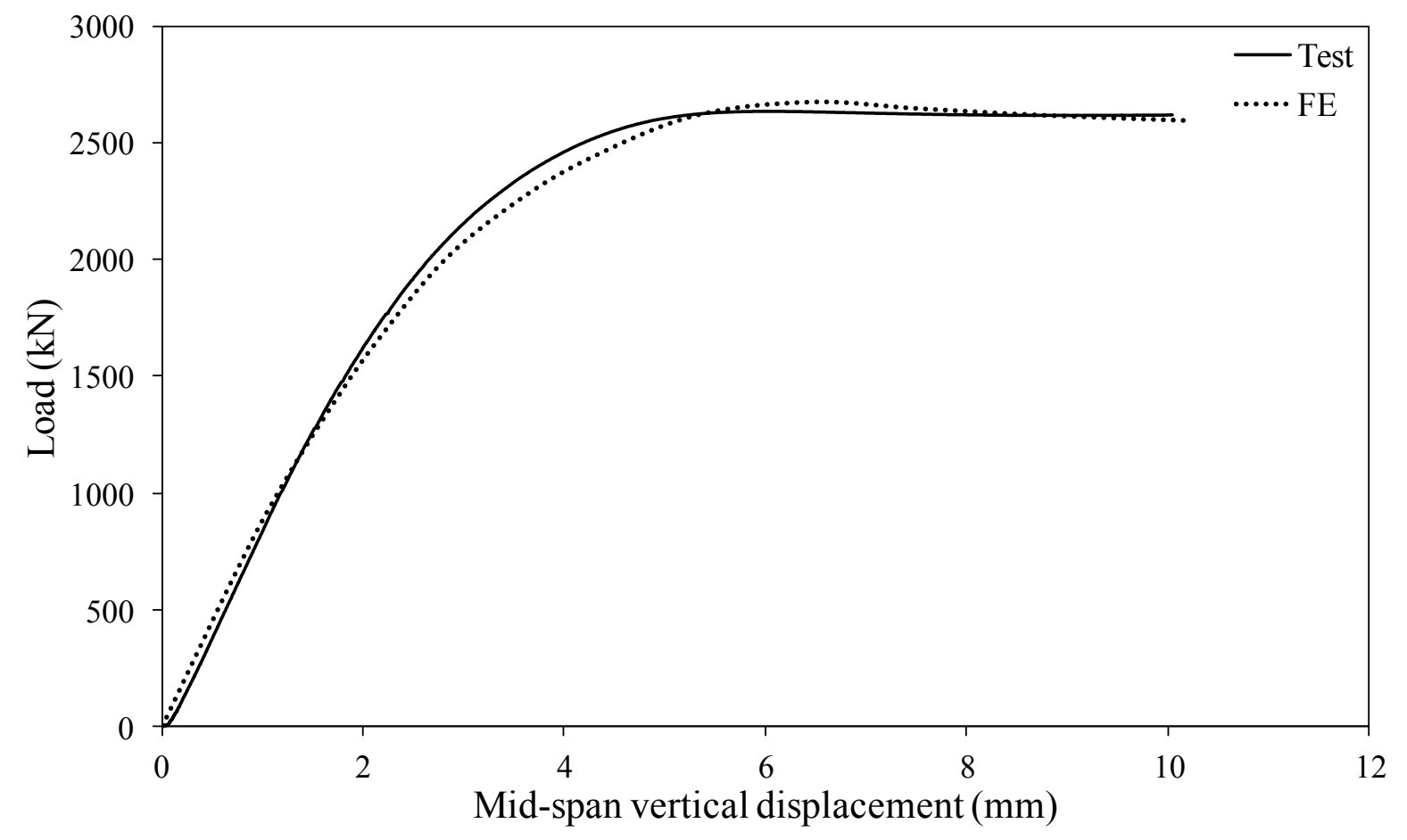

Fig. 17: Experimental and numerical load-mid-span vertical displacement curve for the plate girder I $-600 \times 200 \times 12 \times 8-1$.

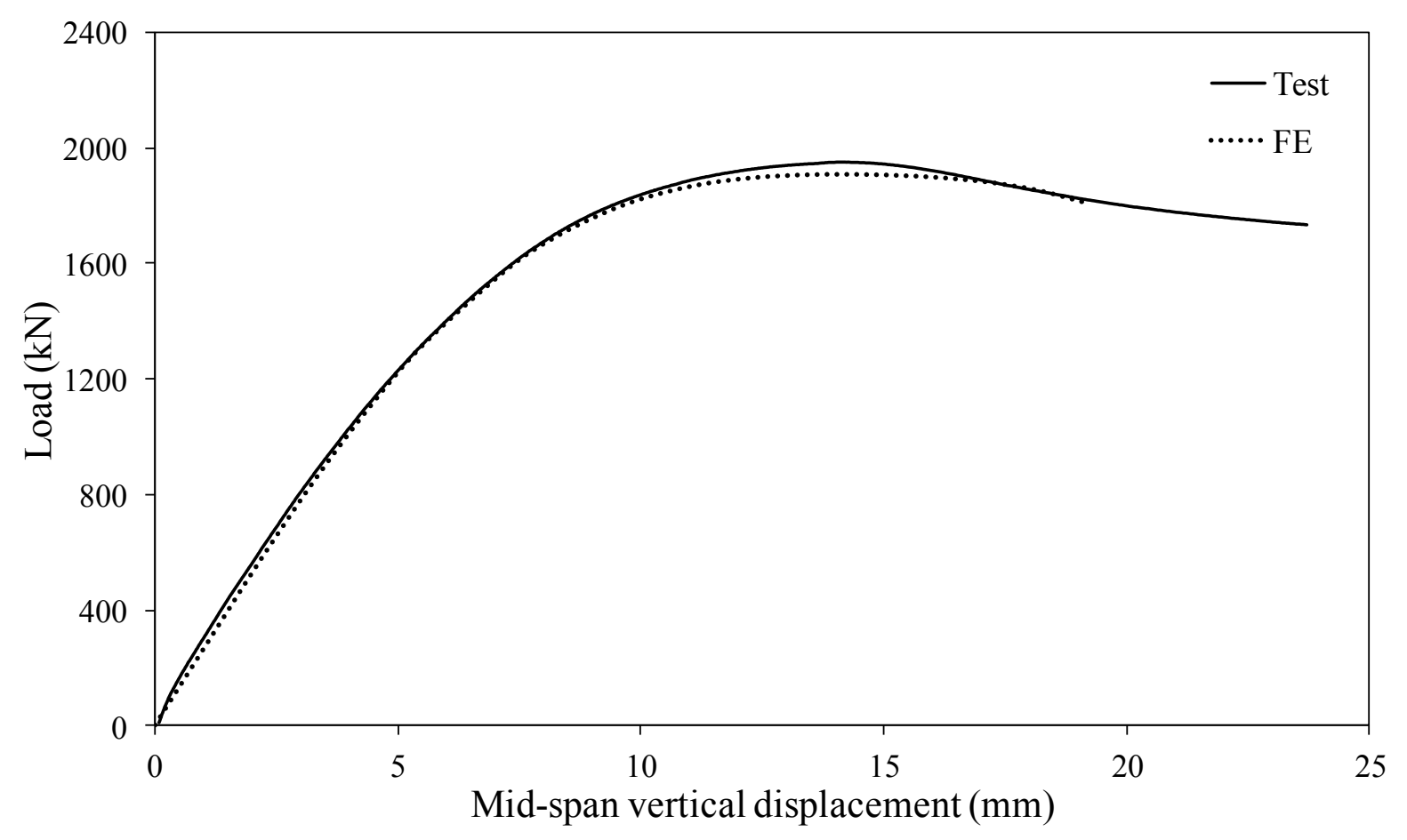

Fig. 18: Experimental and numerical load-mid-span vertical displacement curve for the plate girder I $-600 \times 200 \times 12 \times 8-2$. 


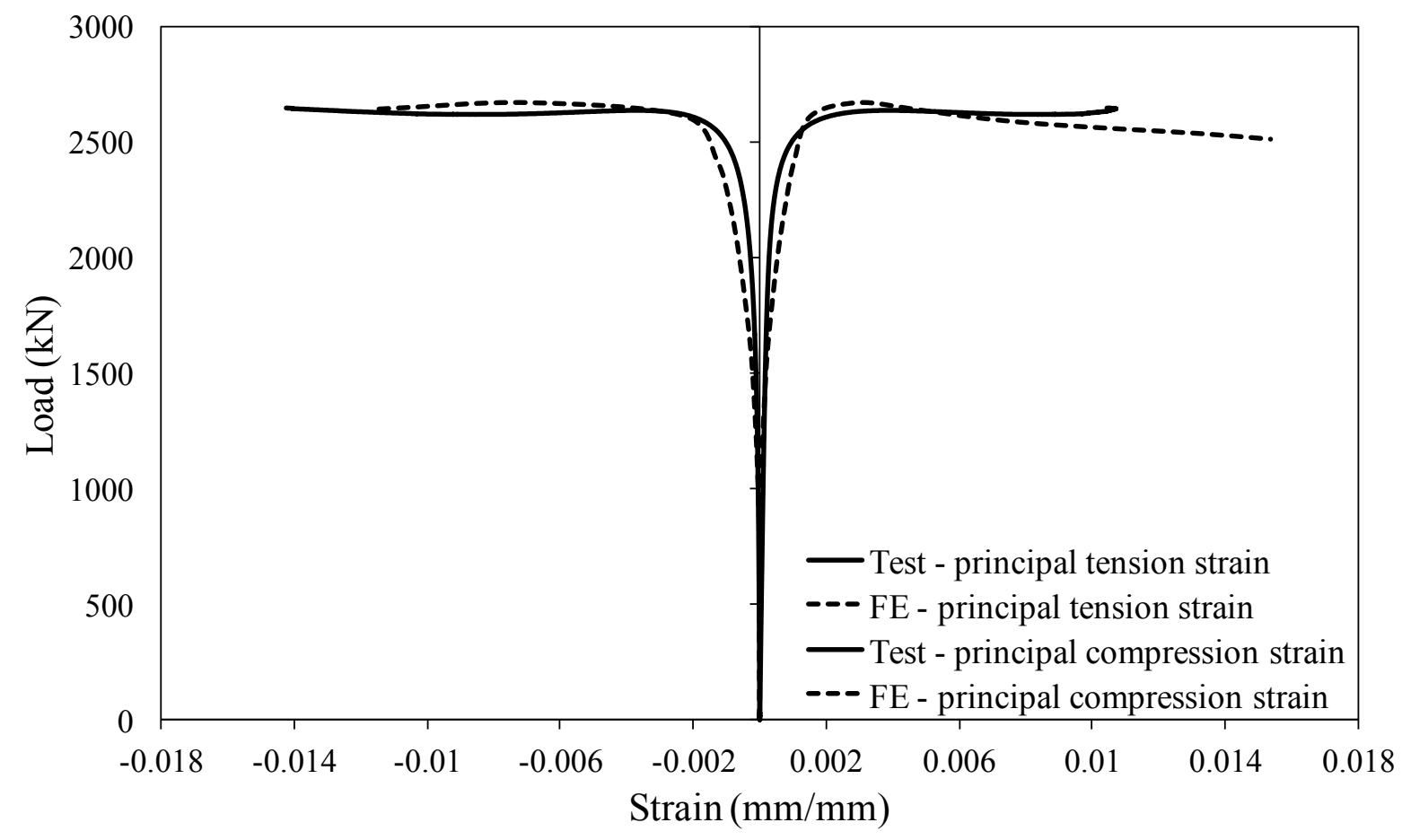

Fig. 19: Evolution of principal strains at centre of web panel for plate girder I $-600 \times 200 \times 12 \times 8-1-$ comparison between experimental and numerical results.

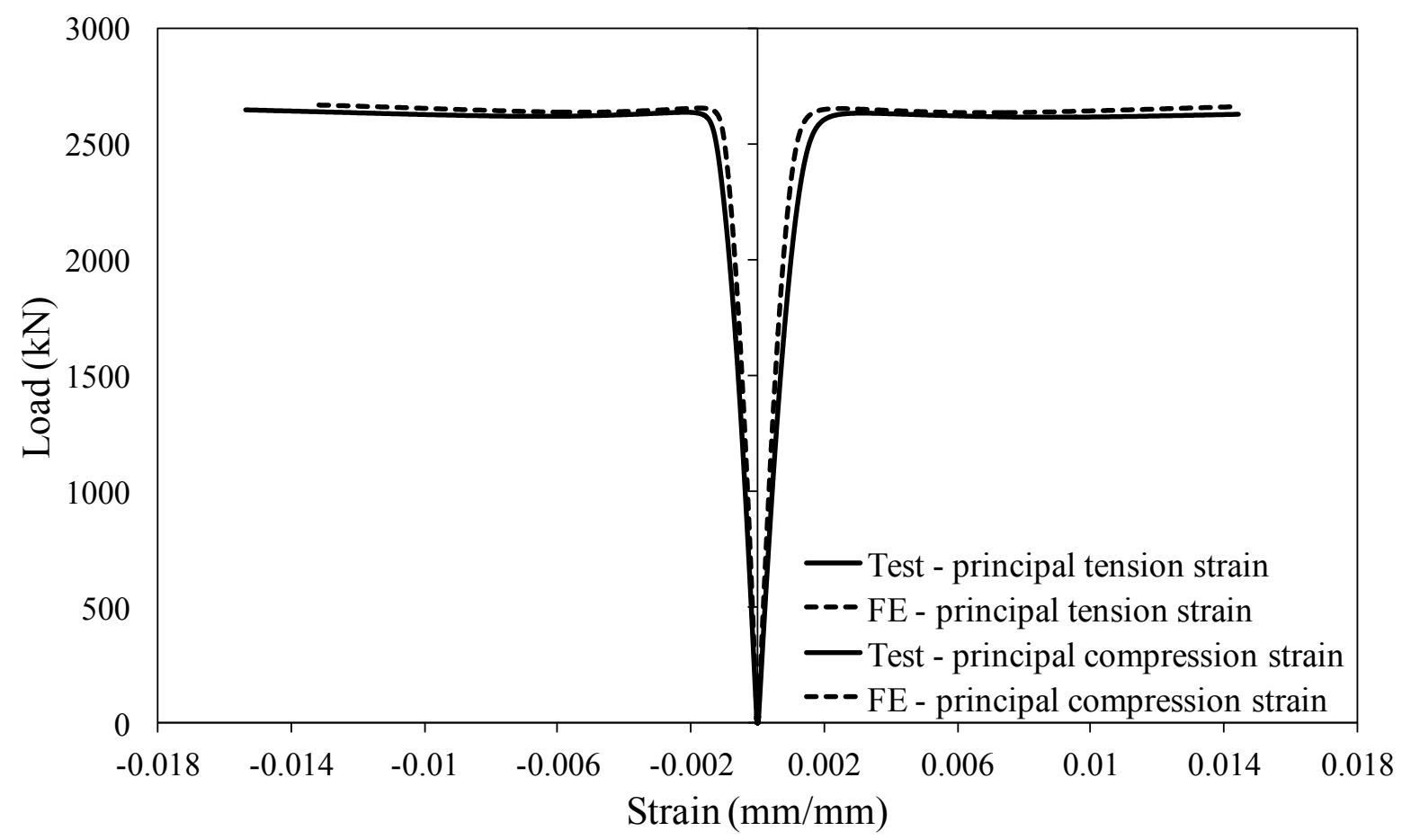

Fig. 20: Evolution of principal strains at corner of web panel for plate girder I $-600 \times 200 \times 12 \times 8-1-$ comparison between experimental and numerical results. 


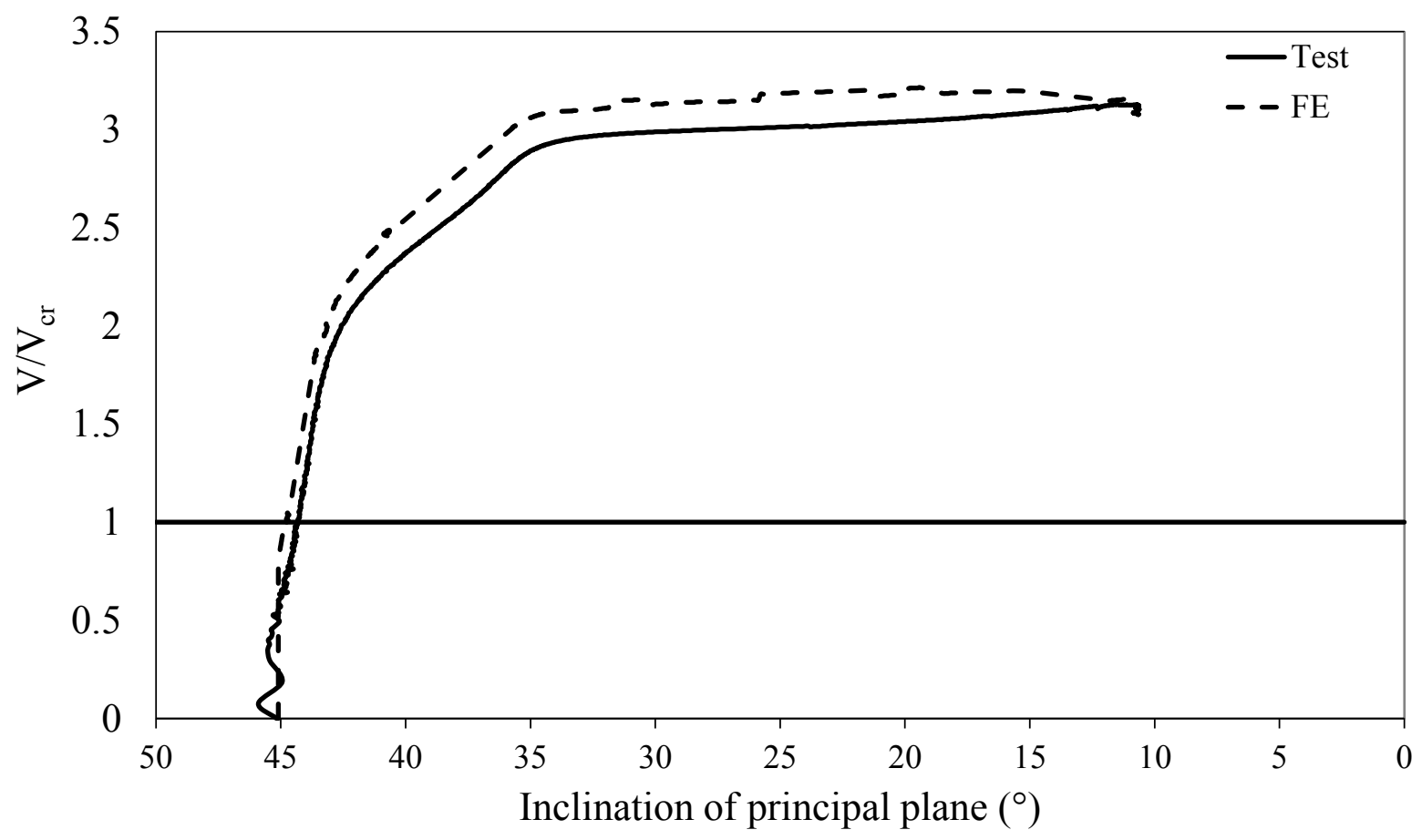

Fig. 21: Inclination of principal plane to horizontal at centre of web panel for plate girder I $-600 \times 200 \times 12 \times 4-1-$ comparison between experimental and numerical results.

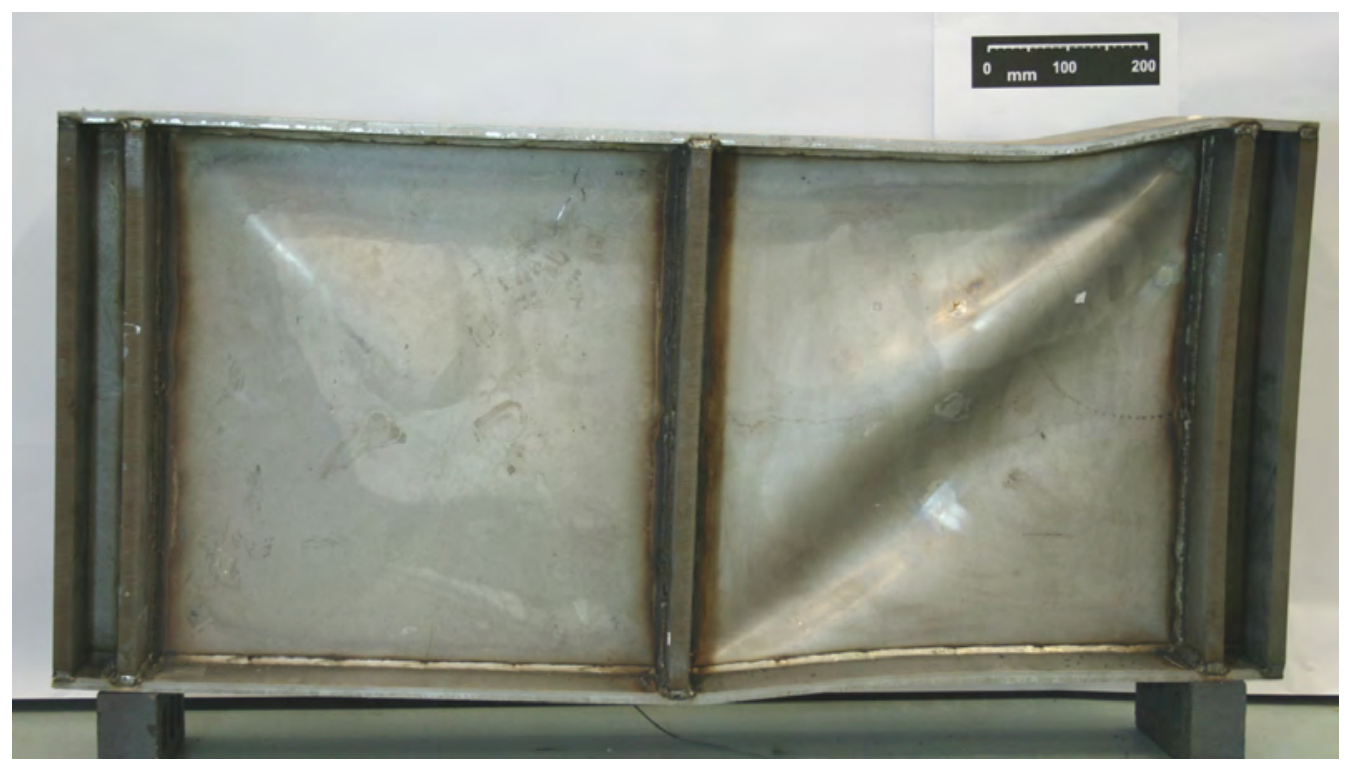

Fig. 22: Typical shear dominant failure mode showing shear buckling of the web for plate girder I $-600 \times 200 \times 12 \times 4-1$. 


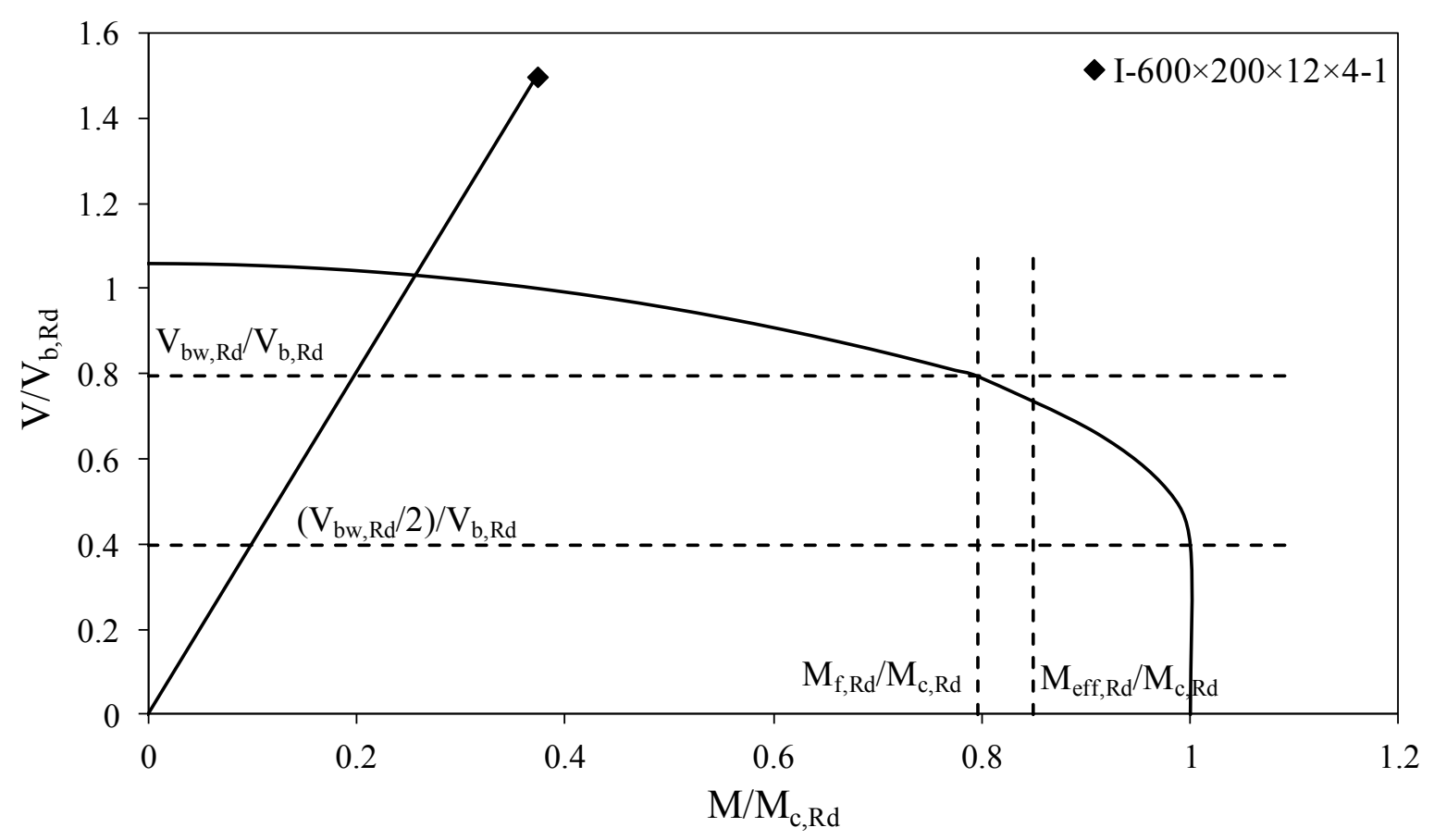

Fig. 23: Moment-shear interaction diagram from EN 1993-1-4 [15] for plate girder I $-600 \times 200 \times 12 \times 4-1$ exhibiting a shear dominant failure mode.

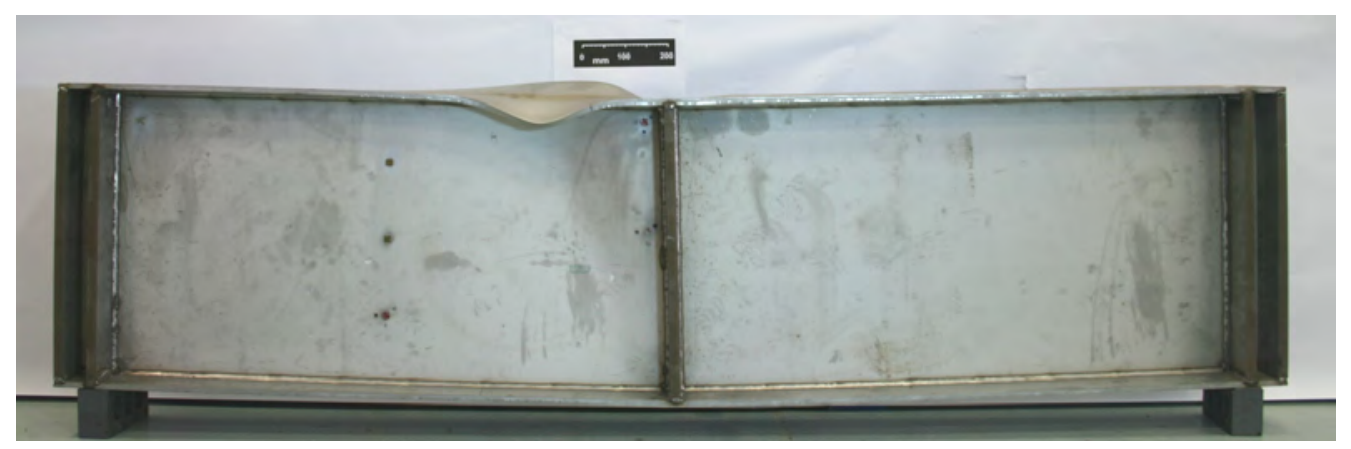

Fig. 24: Typical bending dominant failure mode showing local flange buckling for plate girder I- $600 \times 200 \times 12 \times 10-2$. 


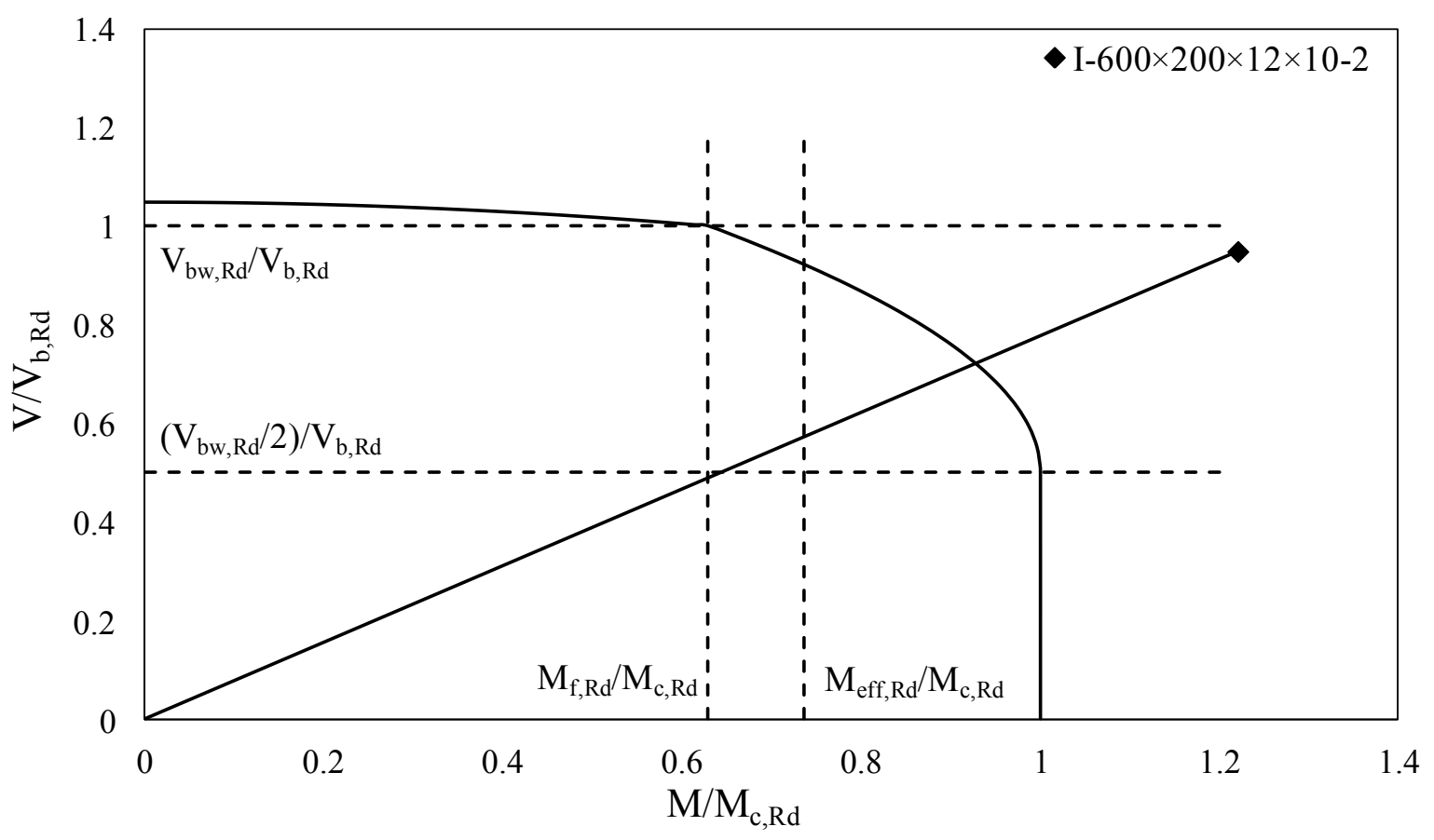

Fig. 25: Moment-shear interaction diagram from EN 1993-1-4 [15] for plate girder I $-600 \times 200 \times 12 \times 10-2$ exhibiting a bending dominant failure mode.

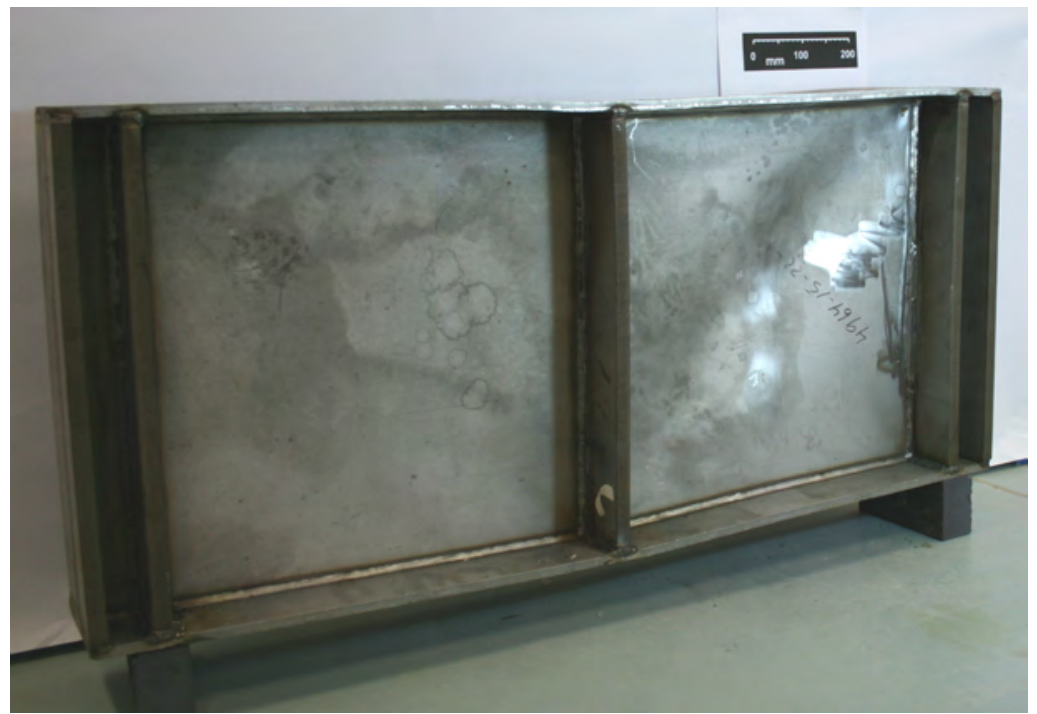

Fig. 26: Typical combined shear plus bending failure mode for plate girder $\mathrm{I}-600 \times 200 \times 12 \times 8-1$. 


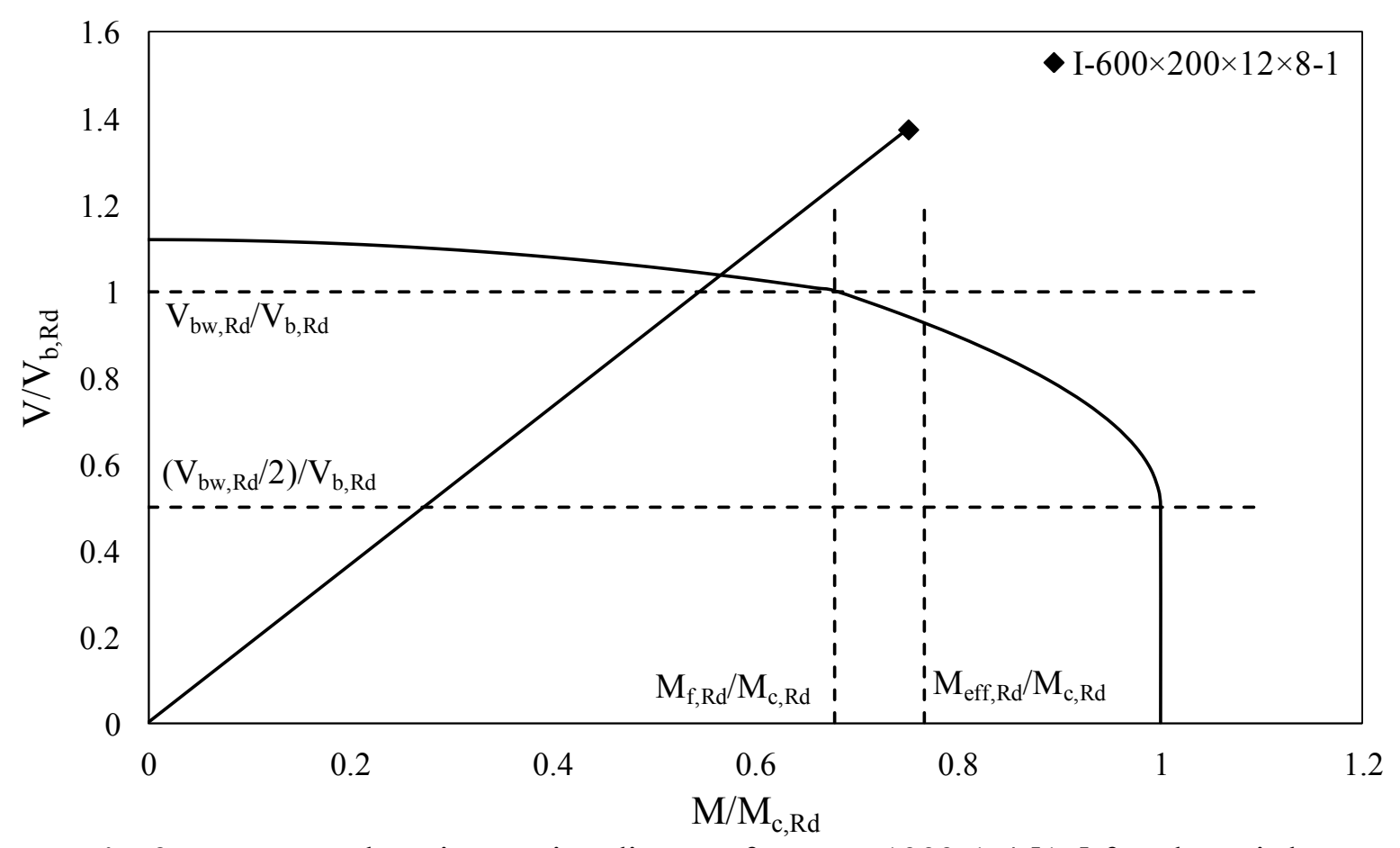

Fig. 27: Moment-shear interaction diagram from EN 1993-1-4 [15] for plate girder I $-600 \times 200 \times 12 \times 8-1$ exhibiting a combined shear-bending failure mode.

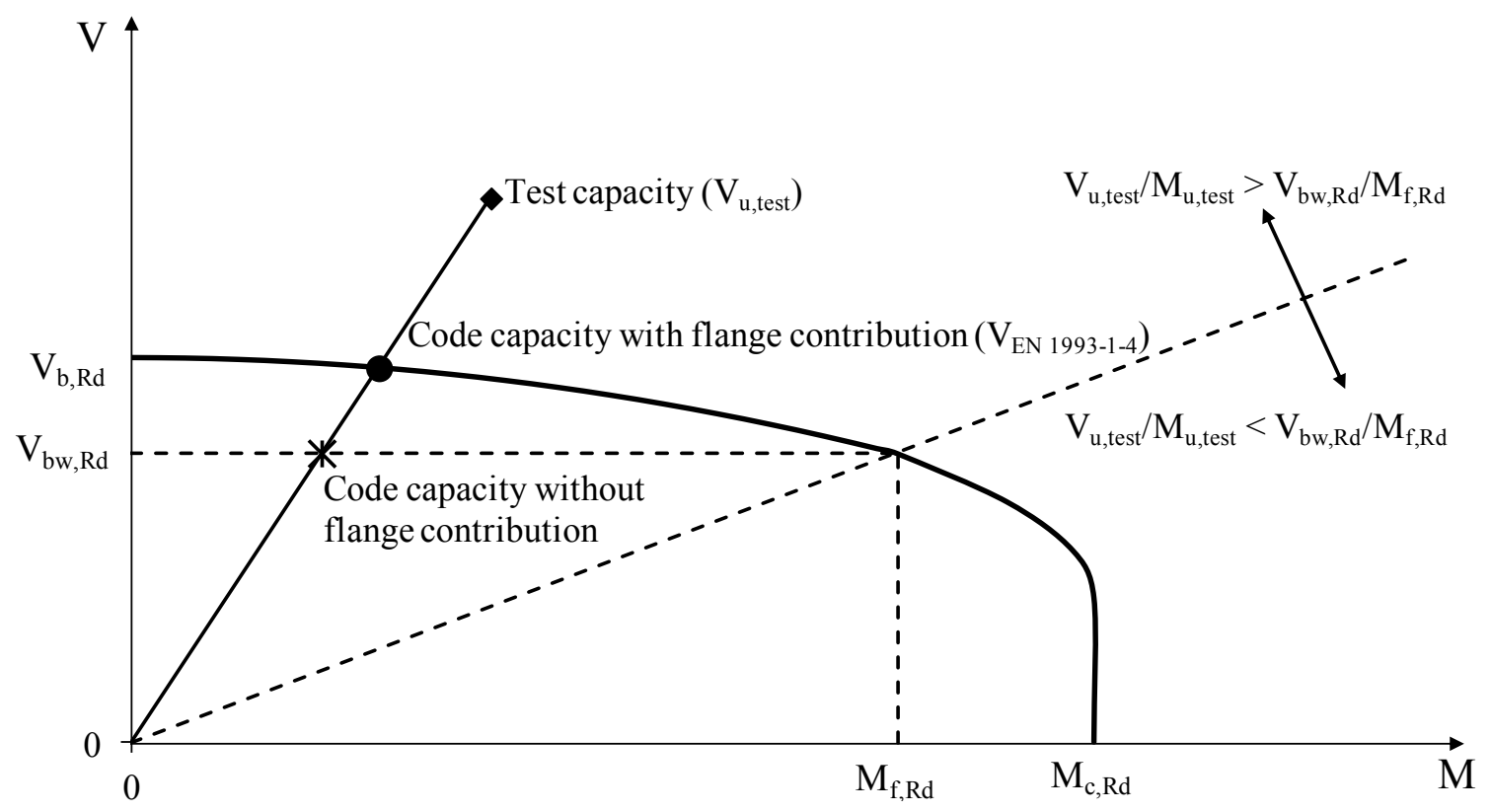

Fig. 28: Moment-shear interaction and definition of a shear dominant failure as $V_{u, \text { test }} / M_{u, \text { test }}$ $>\mathrm{V}_{\mathrm{bw}, \mathrm{Rd}} / \mathrm{M}_{\mathrm{f}, \mathrm{Rd}}$ 


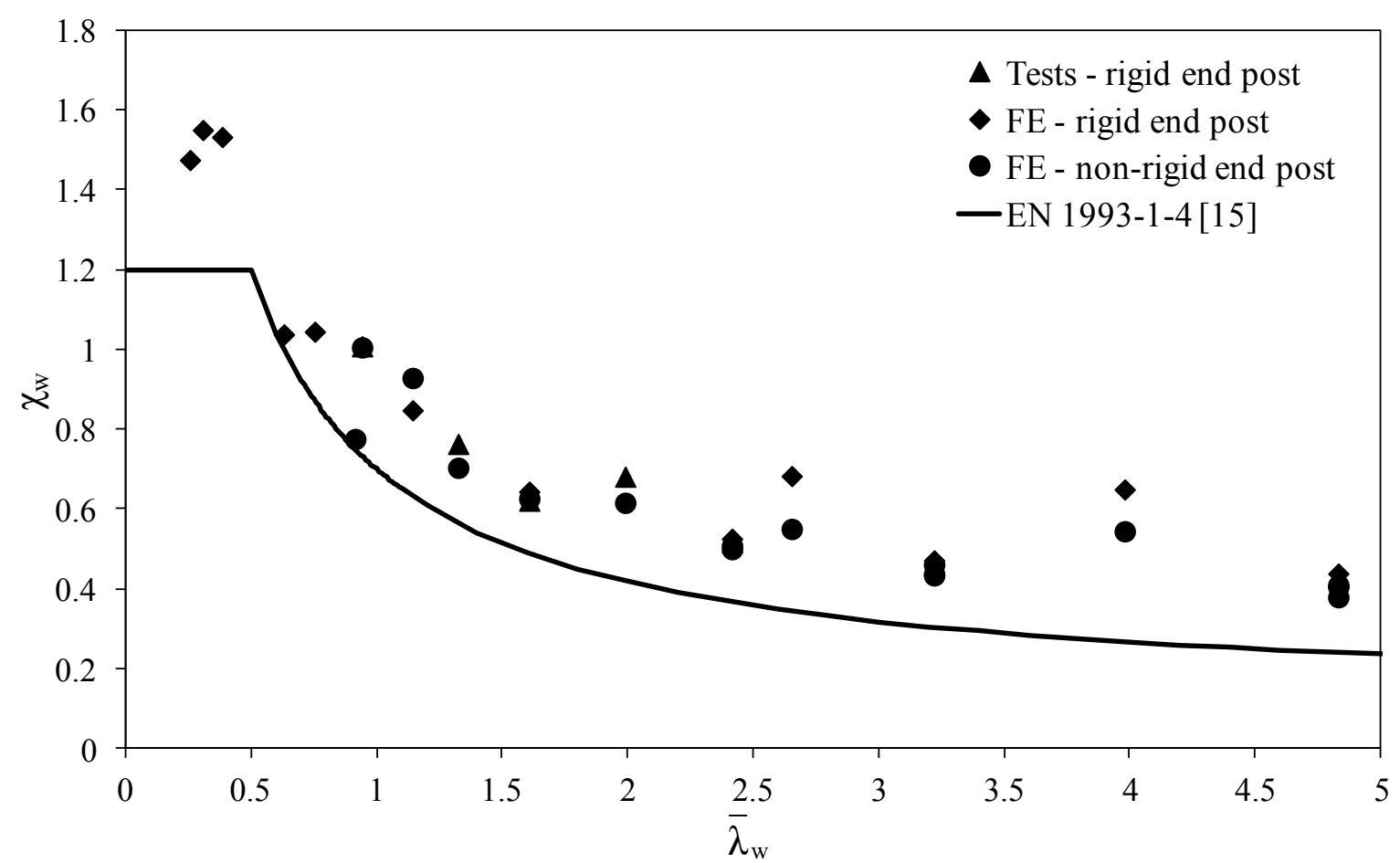

Fig. 29: Comparison of experimental and numerical results for lean duplex stainless steel plate girders with rigid and non-rigid end posts and the EN 1993-1-4 shear design model.

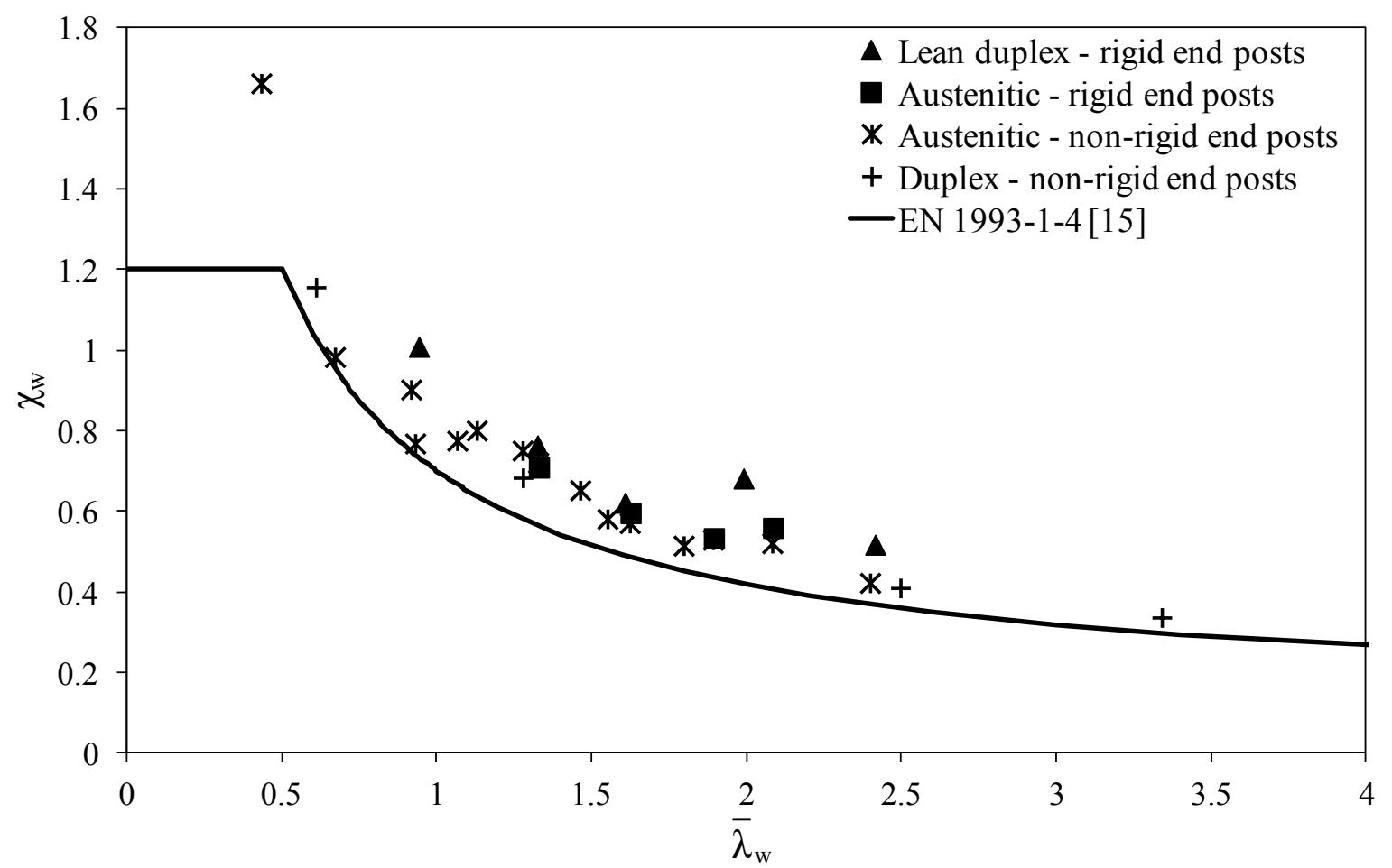

Fig. 30: Comparison of shear buckling resistance for tested plate girders of various stainless steel grades. 
Table 1: Measured material properties from tensile coupon tests, together with comparative transverse tension mill certificate values.

\begin{tabular}{|c|c|c|c|c|c|c|c|c|c|c|c|}
\hline \multirow{3}{*}{$\begin{array}{l}\text { Plate } \\
\text { thickness } \\
(\mathrm{mm})\end{array}$} & \multicolumn{8}{|c|}{ Tensile coupon tests } & \multicolumn{3}{|c|}{$\begin{array}{c}\text { Mill certificate values } \\
\text { (transverse tension) }\end{array}$} \\
\hline & \multirow{2}{*}{$\begin{array}{l}\text { Orientation to } \\
\text { rolling direction }\end{array}$} & \multirow{2}{*}{$\begin{array}{c}E \\
\left(\mathrm{~N} / \mathrm{mm}^{2}\right) \\
\end{array}$} & \multirow{2}{*}{$\begin{array}{c}\sigma_{0.2} \\
\left(\mathrm{~N} / \mathrm{mm}^{2}\right) \\
\end{array}$} & \multirow{2}{*}{$\begin{array}{c}\sigma_{1.0} \\
\left(\mathrm{~N} / \mathrm{mm}^{2}\right)\end{array}$} & \multirow{2}{*}{$\begin{array}{c}\sigma_{\mathrm{u}} \\
\left(\mathrm{N} / \mathrm{mm}^{2}\right) \\
\end{array}$} & \multirow{2}{*}{$\begin{array}{c}\varepsilon_{\mathrm{f}} \\
(\%)\end{array}$} & \multicolumn{2}{|c|}{$\begin{array}{c}\text { Modified } \\
\text { R-O } \\
\text { coefficients } \\
\end{array}$} & \multirow{2}{*}{$\begin{array}{c}\sigma_{0.2} \\
\left(\mathrm{~N} / \mathrm{mm}^{2}\right) \\
\end{array}$} & \multirow{2}{*}{$\begin{array}{c}\sigma_{1.0} \\
\left(\mathrm{~N} / \mathrm{mm}^{2}\right)\end{array}$} & \multirow{2}{*}{$\begin{array}{c}\sigma_{\mathrm{u}} \\
\left(\mathrm{N} / \mathrm{mm}^{2}\right.\end{array}$} \\
\hline & & & & & & & $\mathrm{n}$ & $\mathrm{n}_{0.2,1.0}^{\prime}$ & & & \\
\hline 4.11 & Longitudinal (L1) & 191000 & 486 & 574 & 752 & 56 & 12.0 & 4.0 & 569 & 632 & 753 \\
\hline 6.00 & Longitudinal (L1) & 207000 & 506 & 547 & 719 & 65 & 8.0 & 2.1 & 559 & 621 & 745 \\
\hline 6.22 & Transverse (T1) & 205000 & 549 & 580 & 720 & 55 & 12.0 & 1.9 & 559 & 621 & 745 \\
\hline 8.61 & Longitudinal (L1) & 203000 & 431 & 523 & 714 & 58 & 8.7 & 3.4 & 514 & - & 729 \\
\hline 8.38 & Transverse (T1) & 209000 & 518 & 572 & 766 & 47 & 12.0 & 2.5 & 514 & - & 729 \\
\hline 12.55 & Transverse (T1) & 204000 & 495 & 545 & 714 & 50 & 11.0 & 2.2 & 498 & - & 717 \\
\hline 15.71 & Longitudinal (L1) & 205000 & 564 & 582 & 720 & 55 & 10.3 & 1.3 & 543 & - & 731 \\
\hline 15.78 & Transverse (T1) & 218000 & 556 & 606 & 746 & 39 & 9.4 & 2.5 & 543 & - & 731 \\
\hline 20.82 & Longitudinal (L1) & 214000 & 482 & 550 & 720 & 44 & 12.8 & 2.8 & 498 & - & 717 \\
\hline 20.86 & Transverse (T1) & 219500 & 461 & 545 & - & 54 & - & - & 498 & - & 717 \\
\hline
\end{tabular}


Table 2: Measured material properties from compressive coupon tests, together with comparative transverse tension mill certificate values.

\begin{tabular}{|c|c|c|c|c|c|c|c|c|}
\hline \multirow{3}{*}{$\begin{array}{l}\text { Plate } \\
\text { thickness } \\
(\mathrm{mm})\end{array}$} & \multicolumn{6}{|c|}{ Compressive coupon tests } & \multicolumn{2}{|c|}{$\begin{array}{l}\text { Mill certificate values } \\
\text { (transverse tension) }\end{array}$} \\
\hline & \multirow{2}{*}{$\begin{array}{l}\text { Orientation to } \\
\text { rolling direction }\end{array}$} & \multirow{2}{*}{$\begin{array}{c}E \\
\left(\mathrm{~N} / \mathrm{mm}^{2}\right)\end{array}$} & \multirow{2}{*}{$\begin{array}{c}\sigma_{0.2} \\
\left(\mathrm{~N} / \mathrm{mm}^{2}\right)\end{array}$} & \multirow{2}{*}{$\begin{array}{c}\sigma_{1.0} \\
\left(\mathrm{~N} / \mathrm{mm}^{2}\right)\end{array}$} & \multicolumn{2}{|c|}{$\begin{array}{c}\text { Modified } \\
\text { R-O coefficients }\end{array}$} & \multirow{2}{*}{$\begin{array}{c}\sigma_{0.2} \\
\left(\mathrm{~N} / \mathrm{mm}^{2}\right) \\
\end{array}$} & \multirow{2}{*}{$\begin{array}{c}\sigma_{1.0} \\
\left(\mathrm{~N} / \mathrm{mm}^{2}\right)\end{array}$} \\
\hline & & & & & $\mathrm{n}$ & $\mathrm{n}_{0.2,1.0}^{\prime}$ & & \\
\hline 4.08 & Longitudinal (L1) & 201000 & 494 & 580 & 6.9 & 2.0 & 569 & 632 \\
\hline 4.13 & Transverse (T1) & 213000 & 550 & 619 & 5.3 & 1.6 & 569 & 632 \\
\hline 6.02 & Longitudinal (L1) & 195000 & 488 & 562 & 6.3 & 2.0 & 559 & 621 \\
\hline 6.11 & Transverse (T1) & 212000 & 557 & 614 & 8.0 & 1.5 & 559 & 621 \\
\hline 8.51 & Longitudinal (L1) & - & - & - & - & - & 514 & - \\
\hline 8.6 & Transverse (T1) & 207000 & 492 & 569 & 5.5 & 1.9 & 514 & - \\
\hline 10.65 & Longitudinal (L1) & 201000 & 461 & 539 & 6.0 & 1.9 & 505 & - \\
\hline 10.68 & Transverse (T1) & 201000 & 500 & 570 & 6.1 & 1.8 & 505 & - \\
\hline 12.57 & Longitudinal (L1) & 199000 & 447 & 521 & 5.3 & 1.7 & 498 & - \\
\hline 12.54 & Transverse (T1) & 209000 & 488 & 569 & 6.0 & 1.7 & 498 & - \\
\hline 15.78 & Longitudinal (L1) & 212000 & 488 & 573 & 6.2 & 1.6 & 543 & - \\
\hline 15.79 & Transverse (T1) & 205000 & 509 & 591 & 6.0 & 1.8 & 543 & - \\
\hline 20.92 & Longitudinal (L1) & - & - & - & - & - & 498 & - \\
\hline 20.67 & Transverse (T1) & 202000 & 464 & 543 & 5.9 & 1.6 & 498 & - \\
\hline
\end{tabular}

Table 3: Measured dimensions of plate girders and key test results.

\begin{tabular}{|c|c|c|c|c|c|c|c|c|c|c|c|c|c|c|c|c|}
\hline Plate girder & $\begin{array}{c}\mathrm{L} \\
(\mathrm{mm})\end{array}$ & $\begin{array}{c}\mathrm{a} \\
(\mathrm{mm})\end{array}$ & $\begin{array}{c}\mathrm{e} \\
(\mathrm{mm})\end{array}$ & $\begin{array}{c}\mathrm{h}_{\mathrm{w}} \\
(\mathrm{mm})\end{array}$ & $\begin{array}{c}\mathrm{b} \\
(\mathrm{mm})\end{array}$ & $\begin{array}{c}\mathrm{t}_{\mathrm{f}} \\
(\mathrm{mm})\end{array}$ & $\begin{array}{c}\mathrm{t}_{\mathrm{w}} \\
(\mathrm{mm})\end{array}$ & $\begin{array}{c}\mathrm{t}_{\mathrm{s}} \\
(\mathrm{mm})\end{array}$ & $\begin{array}{c}\mathrm{b}_{\mathrm{s}} \\
(\mathrm{mm}) \\
\end{array}$ & $\mathrm{a} / \mathrm{h}_{\mathrm{w}}$ & $\bar{\lambda}_{\mathrm{w}}$ & $\begin{array}{c}\mathrm{V}_{\mathrm{cr}} \\
(\mathrm{kN})\end{array}$ & $\begin{array}{l}\mathrm{V}_{\mathrm{u}, \text { test }} \\
(\mathrm{kN}) \\
\end{array}$ & $\begin{array}{l}\mathrm{M}_{\mathrm{u}, \text { test }} \\
(\mathrm{kNm})\end{array}$ & $\begin{array}{c}\mathrm{c}_{\text {test }} \\
(\mathrm{mm})\end{array}$ & $\begin{array}{c}\text { Observed } \\
\text { failure } \\
\text { mode }\end{array}$ \\
\hline $\mathrm{I}-600 \times 200 \times 12 \times 4-1$ & 1360 & 600 & 80.0 & 598.8 & 200.1 & 12.4 & 4.1 & 20.9 & 98.0 & 1.0 & 1.99 & 180 & 562 & 337 & 202 & Shear \\
\hline $\mathrm{I}-600 \times 200 \times 12 \times 6-1$ & 1360 & 600 & 80.0 & 599.9 & 199.8 & 12.3 & 6.2 & 20.6 & 96.8 & 1.0 & 1.32 & 626 & 888 & 888 & 193 & Shear \\
\hline $\mathrm{I}-600 \times 200 \times 12 \times 8-1$ & 1360 & 600 & 80.0 & 600.3 & 200.1 & 12.5 & 8.2 & 20.6 & 96.0 & 1.0 & 0.94 & 1484 & 1326 & 1326 & - & Combined \\
\hline $\mathrm{I}-600 \times 200 \times 12 \times 10-1$ & 1360 & 600 & 80.0 & 599.2 & 200.1 & 12.4 & 10.2 & 20.6 & 94.9 & 1.0 & 0.75 & 2877 & 1838 & 1838 & - & Bending \\
\hline $\mathrm{I}-600 \times 200 \times 12 \times 4-2$ & 2560 & 1200 & 80.0 & 600.0 & 200.1 & 12.6 & 4.1 & 20.8 & 98.0 & 2.0 & 2.41 & 122 & 396 & 475 & 285 & Shear \\
\hline $\mathrm{I}-600 \times 200 \times 12 \times 6-2$ & 2560 & 1200 & 80.0 & 600.9 & 200.0 & 12.3 & 6.0 & 20.8 & 97.0 & 2.0 & 1.61 & 425 & 682 & 818 & 315 & Shear \\
\hline I- $600 \times 200 \times 12 \times 8-2$ & 2560 & 1200 & 80.0 & 600.0 & 199.8 & 12.3 & 8.4 & 20.6 & 95.7 & 2.0 & 1.14 & 1007 & 976 & 1172 & - & Combined \\
\hline $\mathrm{I}-600 \times 200 \times 12 \times 10-2$ & 2560 & 1200 & 80.0 & 600.1 & 200.4 & 12.6 & 10.6 & 20.9 & 94.9 & 2.0 & 0.91 & 1953 & 1162 & 1395 & - & Bending \\
\hline $\mathrm{I}-600 \times 200 \times 15 \times 15-2$ & 2560 & 1200 & 80.0 & 599.0 & 200.1 & 15.3 & 15.0 & 20.6 & 92.5 & 2.0 & 0.65 & 6817 & 1801 & 2162 & - & Bending \\
\hline
\end{tabular}


Table 4: Comparison between experimental and numerical results.

\begin{tabular}{|l|c|c|c|c|c|c|}
\hline Plate girder & $\begin{array}{c}\omega_{\mathrm{D} \& \mathrm{~W}} \\
(\mathrm{~mm})\end{array}$ & $\mathrm{a} / \mathrm{h}_{\mathrm{w}}$ & $\bar{\lambda}_{\mathrm{w}}$ & $\mathrm{V}_{\mathrm{u}, \text { test }}(\mathrm{kN})$ & $\mathrm{V}_{\mathrm{u}, \mathrm{FE}}(\mathrm{kN})$ & $\mathrm{V}_{\mathrm{u}, \mathrm{FE}} / \mathrm{V}_{\mathrm{u}, \text { test }}$ \\
\hline $\mathrm{I}-600 \times 200 \times 12 \times 4-1$ & 0.25 & 1.00 & 1.99 & 562 & 596 & 1.06 \\
\hline $\mathrm{I}-600 \times 200 \times 12 \times 6-1$ & 0.16 & 1.00 & 1.32 & 888 & 893 & 1.01 \\
\hline $\mathrm{I}-600 \times 200 \times 12 \times 8-1$ & 0.11 & 1.00 & 0.94 & 1326 & 1336 & 1.01 \\
\hline $\mathrm{I}-600 \times 200 \times 12 \times 10-1$ & 0.088 & 1.00 & 0.75 & 1838 & 1753 & 0.95 \\
\hline $\mathrm{I}-600 \times 200 \times 12 \times 4-2$ & 0.25 & 2.00 & 2.41 & 396 & 406 & 1.03 \\
\hline $\mathrm{I}-600 \times 200 \times 12 \times 6-2$ & 0.16 & 2.00 & 1.61 & 682 & 700 & 1.03 \\
\hline $\mathrm{I}-600 \times 200 \times 12 \times 8-2$ & 0.11 & 2.00 & 1.14 & 976 & 954 & 0.98 \\
\hline $\mathrm{I}-600 \times 200 \times 12 \times 10-2$ & 0.088 & 2.00 & 0.91 & 1162 & 1152 & 0.99 \\
\hline $\mathrm{I}-600 \times 200 \times 15 \times 15-2$ & 0.067 & 2.00 & 0.65 & 1801 & 1747 & 0.97 \\
\hline Mean & & & & & & 1.00 \\
\hline COV & & & & & & 0.03 \\
\hline
\end{tabular}

Table 5: Comparisons of experimental results with EN 1993-1-4 predictions.

\begin{tabular}{|l|c|c|c|c|c|}
\hline Plate girder & $\mathrm{a} / \mathrm{h}_{\mathrm{w}}$ & $\bar{\lambda}_{\mathrm{w}}$ & $\mathrm{V}_{\mathrm{u}, \text { test }}(\mathrm{kN})$ & $\mathrm{V}_{\mathrm{EN} \mathrm{1993-1-4}}(\mathrm{kN})$ & $\mathrm{V}_{\mathrm{u}, \text { test }} / \mathrm{V}_{\mathrm{EN} \mathrm{1993-1-4}}$ \\
\hline $\mathrm{I}-600 \times 200 \times 12 \times 4-1$ & 1.00 & 1.99 & 562 & 386 & 1.46 \\
\hline $\mathrm{I}-600 \times 200 \times 12 \times 6-1$ & 1.00 & 1.32 & 888 & 693 & 1.28 \\
\hline $\mathrm{I}-600 \times 200 \times 12 \times 8-1$ & 1.00 & 0.94 & 1326 & 999 & 1.33 \\
\hline $\mathrm{I}-600 \times 200 \times 12 \times 10-1$ & 1.00 & 0.75 & 1838 & 1274 & 1.44 \\
\hline $\mathrm{I}-600 \times 200 \times 12 \times 4-2$ & 2.00 & 2.41 & 396 & 297 & 1.33 \\
\hline $\mathrm{I}-600 \times 200 \times 12 \times 6-2$ & 2.00 & 1.61 & 682 & 546 & 1.25 \\
\hline $\mathrm{I}-600 \times 200 \times 12 \times 8-2$ & 2.00 & 1.14 & 976 & 652 & 1.50 \\
\hline $\mathrm{I}-600 \times 200 \times 12 \times 10-2$ & 2.00 & 0.91 & 1162 & 699 & 1.66 \\
\hline $\mathrm{I}-600 \times 200 \times 15 \times 15-2$ & 2.00 & 0.65 & 1801 & 1489 & 1.21 \\
\hline Mean & & & & & \\
\hline COV & & & & & \\
\hline
\end{tabular}


Table 6: Comparisons of parametric FE results on plate girders with rigid end posts with the EN 1993-1-4 predictions.

\begin{tabular}{|l|c|c|c|c|c|}
\hline Plate girder & $\mathrm{a} / \mathrm{h}_{\mathrm{w}}$ & $\bar{\lambda}_{\mathrm{w}}$ & $\mathrm{V}_{\mathrm{u}, \mathrm{FE}}(\mathrm{kN})$ & $\mathrm{V}_{\mathrm{EN} 1993-1-4}(\mathrm{kN})$ & $\mathrm{V}_{\mathrm{u}, \mathrm{FE}} / \mathrm{V}_{\mathrm{EN} 1993-1-4}$ \\
\hline $\mathrm{I}-700 \times 200 \times 60 \times 30-0.86$ & 0.86 & 0.26 & 8050 & 6655 & 1.21 \\
\hline $\mathrm{I}-700 \times 200 \times 60 \times 25-0.86$ & 0.86 & 0.31 & 7050 & 5944 & 1.19 \\
\hline $\mathrm{I}-700 \times 200 \times 60 \times 20-0.86$ & 0.86 & 0.38 & 5900 & 4963 & 1.19 \\
\hline $\mathrm{I}-600 \times 200 \times 15 \times 12-1$ & 1.00 & 0.63 & 2056 & 1917 & 1.07 \\
\hline $\mathrm{I}-600 \times 200 \times 15 \times 10-1$ & 1.00 & 0.75 & 1708 & 1473 & 1.16 \\
\hline $\mathrm{I}-600 \times 200 \times 12 \times 3-1$ & 1.00 & 2.65 & 443 & 270 & 1.64 \\
\hline $\mathrm{I}-600 \times 200 \times 12 \times 2-1$ & 1.00 & 3.98 & 303 & 171 & 1.77 \\
\hline $\mathrm{I}-600 \times 200 \times 15 \times 6-2$ & 2.00 & 1.61 & 731 & 583 & 1.25 \\
\hline $\mathrm{I}-600 \times 200 \times 15 \times 4-2$ & 2.00 & 2.41 & 428 & 323 & 1.33 \\
\hline $\mathrm{I}-600 \times 200 \times 15 \times 3-2$ & 2.00 & 3.22 & 307 & 222 & 1.38 \\
\hline $\mathrm{I}-600 \times 200 \times 15 \times 2-2$ & 2.00 & 4.83 & 204 & 136 & 1.50 \\
\hline $\mathrm{I}-600 \times 200 \times 12 \times 3-2$ & 2.00 & 3.22 & 281 & 202 & 1.39 \\
\hline $\mathrm{I}-600 \times 200 \times 12 \times 2-2$ & 2.00 & 4.83 & 179 & 123 & 1.46 \\
\hline Mean & & & & & 1.35 \\
\hline COV & & & & & 0.15 \\
\hline
\end{tabular}

Table 7: Comparisons of parametric FE results on plate girders with non-rigid end posts with the EN 1993-1-4 predictions.

\begin{tabular}{|c|c|c|c|c|c|}
\hline Plate girder & $\mathrm{a} / \mathrm{h}_{\mathrm{w}}$ & $\bar{\lambda}_{\mathrm{w}}$ & $\mathrm{V}_{\mathrm{u}, \mathrm{FE}}(\mathrm{kN})$ & $\mathrm{V}_{\mathrm{EN} \mathrm{1993-1-4}}(\mathrm{kN})$ & $\mathrm{V}_{\mathrm{u}, \mathrm{FE}} / \mathrm{V}_{\mathrm{EN} 1993-1-4}$ \\
\hline I- $600 \times 200 \times 15 \times 12-1$ & 1.00 & 0.63 & 2074 & 1917 & 1.08 \\
\hline I- $600 \times 200 \times 15 \times 10-1$ & 1.00 & 0.75 & 1734 & 1473 & 1.18 \\
\hline I- $600 \times 200 \times 12 \times 10-1$ & 1.00 & 0.75 & 1823 & 1344 & 1.36 \\
\hline $\mathrm{I}-600 \times 200 \times 12 \times 8-1$ & 1.00 & 0.94 & 1323 & 999 & 1.32 \\
\hline $\mathrm{I}-600 \times 200 \times 12 \times 6-1$ & 1.00 & 1.32 & 830 & 693 & 1.20 \\
\hline $\mathrm{I}-600 \times 200 \times 12 \times 4-1$ & 1.00 & 1.99 & 519 & 387 & 1.34 \\
\hline I- $600 \times 200 \times 12 \times 3-1$ & 1.00 & 2.65 & 375 & 270 & 1.39 \\
\hline $\mathrm{I}-600 \times 200 \times 12 \times 2-1$ & 1.00 & 3.98 & 267 & 171 & 1.56 \\
\hline $\mathrm{I}-600 \times 200 \times 15 \times 6-2$ & 2.00 & 1.61 & 714 & 583 & 1.22 \\
\hline $\mathrm{I}-600 \times 200 \times 15 \times 4-2$ & 2.00 & 2.41 & 411 & 323 & 1.27 \\
\hline $\mathrm{I}-600 \times 200 \times 15 \times 3-2$ & 2.00 & 3.22 & 290 & 222 & 1.31 \\
\hline $\mathrm{I}-600 \times 200 \times 15 \times 2-2$ & 2.00 & 4.83 & 194 & 129 & 1.51 \\
\hline I- $600 \times 200 \times 15 \times 15-2$ & 2.00 & 0.65 & 1747 & 1489 & 1.17 \\
\hline I- $600 \times 200 \times 12 \times 10-2$ & 2.00 & 0.91 & 1151 & 883 & 1.30 \\
\hline $\mathrm{I}-600 \times 200 \times 12 \times 8-2$ & 2.00 & 1.14 & 950 & 725 & 1.31 \\
\hline $\mathrm{I}-600 \times 200 \times 12 \times 6-2$ & 2.00 & 1.61 & 688 & 559 & 1.23 \\
\hline $\mathrm{I}-600 \times 200 \times 12 \times 4-2$ & 2.00 & 2.41 & 390 & 298 & 1.31 \\
\hline $\mathrm{I}-600 \times 200 \times 12 \times 3-2$ & 2.00 & 3.22 & 268 & 202 & 1.33 \\
\hline $\mathrm{I}-600 \times 200 \times 12 \times 2-2$ & 2.00 & 4.83 & 170 & 123 & 1.39 \\
\hline Mean & & & & & 1.30 \\
\hline $\mathrm{COV}$ & & & & & 0.09 \\
\hline
\end{tabular}


Table 8: Comparison between FE results for rigid and non-rigid end post plate girders.

\begin{tabular}{|l|c|c|c|c|c|}
\hline Plate girder & $\mathrm{a} / \mathrm{h}_{\mathrm{w}}$ & $\bar{\lambda}_{\mathrm{w}}$ & $\mathrm{V}_{\mathrm{u}, \mathrm{FE}, \text { rigid }}(\mathrm{kN})$ & $\mathrm{V}_{\mathrm{u}, \mathrm{FE}, \text { non-rigid }}(\mathrm{kN})$ & $\mathrm{V}_{\mathrm{u}, \mathrm{FE}, \text { rigid }} / \mathrm{V}_{\mathrm{u}, \mathrm{FE}, \text { non-rigid }}$ \\
\hline $\mathrm{I}-600 \times 200 \times 12 \times 2-1$ & 1.00 & 3.98 & 303 & 267 & 1.14 \\
\hline $\mathrm{I}-600 \times 200 \times 12 \times 3-1$ & 1.00 & 2.65 & 443 & 375 & 1.18 \\
\hline $\mathrm{I}-600 \times 200 \times 12 \times 4-1$ & 1.00 & 1.99 & 596 & 519 & 1.08 \\
\hline $\mathrm{I}-600 \times 200 \times 12 \times 6-1$ & 1.00 & 1.32 & 893 & 830 & 1.01 \\
\hline $\mathrm{I}-600 \times 200 \times 12 \times 8-1$ & 1.00 & 0.94 & 1336 & 1323 & 1.05 \\
\hline $\mathrm{I}-600 \times 200 \times 12 \times 2-2$ & 2.00 & 4.83 & 179 & 170 & 1.05 \\
\hline $\mathrm{I}-600 \times 200 \times 12 \times 3-2$ & 2.00 & 3.22 & 281 & 268 & 1.04 \\
\hline $\mathrm{I}-600 \times 200 \times 12 \times 4-2$ & 2.00 & 2.41 & 406 & 390 & 1.02 \\
\hline $\mathrm{I}-600 \times 200 \times 12 \times 6-2$ & 2.00 & 1.61 & 700 & 688 & 1.00 \\
\hline $\mathrm{I}-600 \times 200 \times 12 \times 8-2$ & 2.00 & 1.14 & 954 & 950 & 1.00 \\
\hline $\mathrm{I}-600 \times 200 \times 12 \times 10-2$ & 2.00 & 0.91 & 1152 & 1151 & 1.00 \\
\hline $\mathrm{I}-600 \times 200 \times 15 \times 15-2$ & 2.00 & 0.65 & 1747 & 1747 & 0.99 \\
\hline $\mathrm{I}-600 \times 200 \times 15 \times 12-1$ & 1.00 & 0.63 & 2056 & 2074 & 0.99 \\
\hline $\mathrm{I}-600 \times 200 \times 15 \times 10-1$ & 1.00 & 0.75 & 1708 & 1734 & 1.02 \\
\hline $\mathrm{I}-600 \times 200 \times 15 \times 6-2$ & 2.00 & 1.61 & 731 & 714 & 1.04 \\
\hline $\mathrm{I}-600 \times 200 \times 15 \times 4-2$ & 2.00 & 2.41 & 428 & 411 & 1.06 \\
\hline $\mathrm{I}-600 \times 200 \times 15 \times 3-2$ & 2.00 & 3.22 & 307 & 290 & 1.05 \\
\hline $\mathrm{I}-600 \times 200 \times 15 \times 2-2$ & 2.00 & 4.83 & 204 & 194 & 1.05 \\
\hline Mean & & & & & 0.05 \\
\hline COV & & & & & \\
\hline
\end{tabular}

